\title{
Eliciting Preferences of
}

\section{Ride-Hailing Users and}

\section{Drivers}

Prateek Bansal, Akanksha Sinha, Rubal Dua, Ricardo Daziano 


\section{About KAPSARC}

The King Abdullah Petroleum Studies and Research Center (KAPSARC) is a non-profit global institution dedicated to independent research into energy economics, policy, technology and the environment across all types of energy. KAPSARC's mandate is to advance the understanding of energy challenges and opportunities facing the world today and tomorrow, through unbiased, independent, and high-caliber research for the benefit of society. KAPSARC is located in Riyadh, Saudi Arabia.

This publication is also available in Arabic.

\section{Legal Notice}

(C) Copyright 2020 King Abdullah Petroleum Studies and Research Center ("KAPSARC"). This Document (and any information, data or materials contained therein) (the "Document") shall not be used without the proper attribution to KAPSARC. The Document shall not be reproduced, in whole or in part, without the written permission of KAPSARC. KAPSARC makes no warranty, representation or undertaking whether expressed or implied, nor does it assume any legal liability, whether direct or indirect, or responsibility for the accuracy, completeness, or usefulness of any information that is contained in the Document. Nothing in the Document constitutes or shall be implied to constitute advice, recommendation or option. The views and opinions expressed in this publication are those of the authors and do not necessarily reflect the official views or position of KAPSARC. 


\section{Key Points}

ystemic transformations are taking place in passenger auto travel. The rise of transportation network companies (TNCs) such as Uber and Lyft has begun to fundamentally alter key aspects of individuals' behavior including vehicle ownership, distance traveled, adoption of alternative fuel vehicles and use of public transit. Such shifts will have major impacts on light-duty passenger vehicles, which account for one-quarter of global oil demand, more than any other sector. To assess the systemlevel impacts of TNCs, the 'micro-decisions' of users and drivers need to be better understood. This study contributes to the nascent field by using a large, unique sample to estimate a) individuals' preferences for being a rider, driver, or non-user of TNC services; b) the propensity of TNC users for 'ride-pooling;' c) TNC drivers' likelihood of switching to vehicles with better fuel economy; and d) the drivers' decisions to buy, rent or lease new vehicles with driving for TNCs as a major consideration. We analyze a sample $(\mathrm{N}=11,902)$ of survey respondents in TNC-served areas in the United States, providing a case study for other countries, including Saudi Arabia, where personal auto travel is the dominant form of transportation.

The key findings of this study:

A population-weighted statistical analysis indicates that ride-hailing services are mainly attracting personal vehicle users as riders, without substantially affecting the demand for public transit. Among ride-hailing users, around $10 \%$ reported postponing the purchase of a new car due to the availability of TNC services.

Mobility option used if the primary option is not available

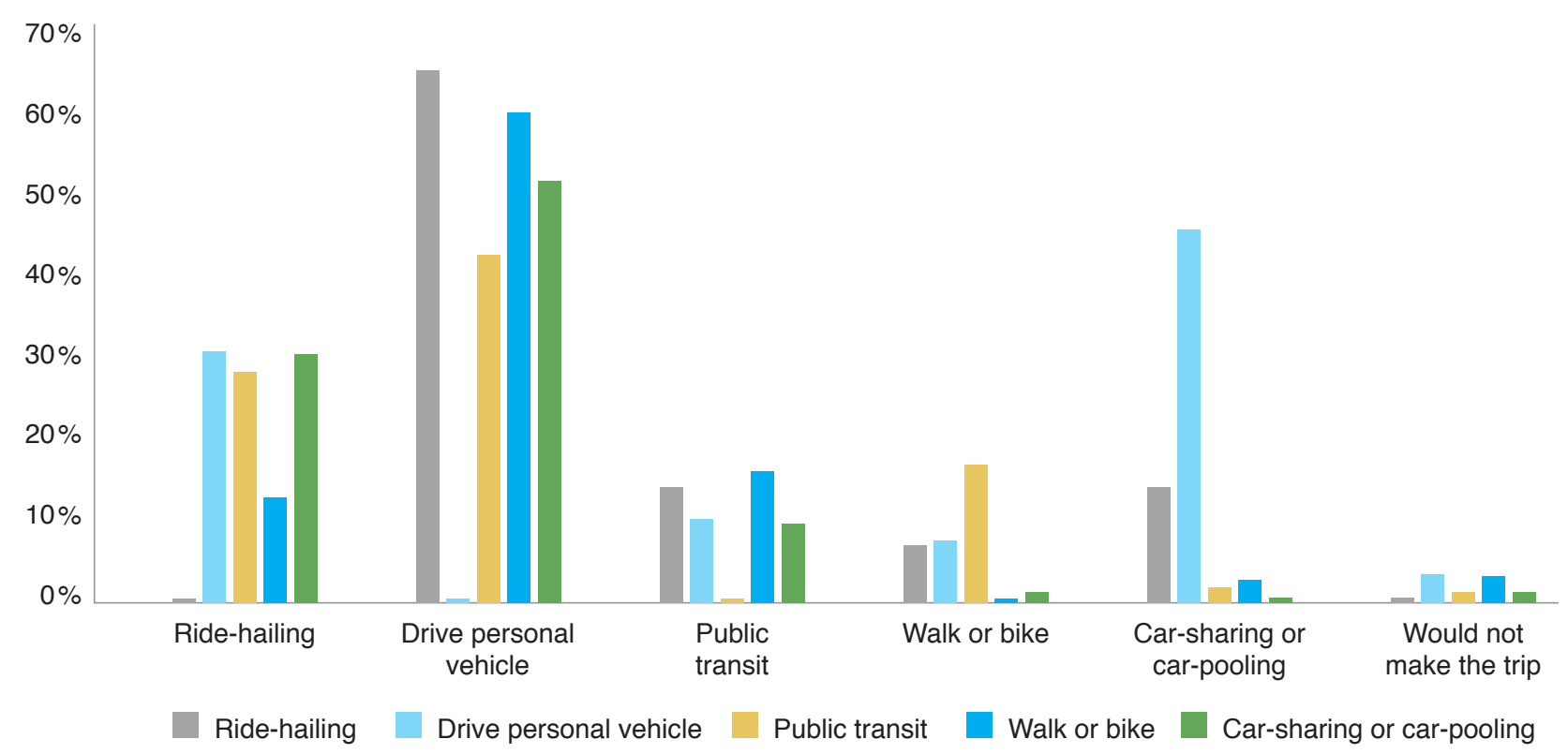

Source: KAPSARC analysis. 


\section{Key Points}

Fitting a multinomial logistic regression model on the propensity of being a rider, driver or non-user of TNC services, we find that the likelihood of being a TNC user rises according to age for someone younger than 44 years, but the pattern reverses for those 44 years and older.

In terms of 'ride-pooling,' older TNC users with higher household vehicle ownership who live in suburban areas are less likely to choose to ride pool.

The majority (65\%) of TNC drivers who drive daily for TNCs indicated that their occupation was a major consideration in vehicle purchase decisions.

Households with drivers who hold postgraduate degrees, drive daily and live in metropolitan areas are more likely to switch to fuel-efficient vehicles. 


\section{Summary}

he 'ride-hailing' services offered by transportation network companies (TNCs) such as Uber and Lyft have rapidly disrupted personal transportation, particularly in cities. Schaller (2018) reports that TNCs provided 2.6 billion rides in 2017 in the United States (U.S.), a $37 \%$ increase from 2016. The rapid increase in the adoption of TNC services can be attributed to the ease of access offered by smartphone applications and the higher availability of cars and drivers compared to regulated, traditional taxi services.

Proponents of TNCs emphasize that ride-hailing services offer consumers alternative transport options, especially in high-demand areas with unreliable and inefficient transit services (Alemi et al. 2018). They also assert that TNCs allow users to give up vehicle ownership and/or reduce vehicle usage - not only by replacing personal vehicle use but also by facilitating multi-modal travel (e.g., ridehailing as a means to reach public transportation). Furthermore, TNCs offer options for 'ride-pooling,' in which multiple customers share a single vehicle; this has immense potential to reduce vehicle miles traveled (VMT) and thus greenhouse gas emissions and traffic congestion (Martin and Shaheen 2011). However, a few studies have highlighted the adverse effects of TNC services, including induced demand for travel and a reduction in public transit ridership in certain areas.

Transportation planners and policymakers are uncertain about the impacts of TNC services on energy use, the environment and traffic problems (Conway et al. 2018). Declines in VMT and vehicle ownership can reduce greenhouse gas emissions (as established in 'car-sharing' literature), but induced demand can negate such gains. These system-level impacts are manifestations of individual-level decisions, both by customers-namely how frequently to use ride- hailing and whether the rides replace driving or public transit-and by TNC drivers, such as how fuel-efficient a vehicle to drive. However, in the absence of sufficient data on individual preferences, transportation authorities and other stakeholders are unable to quantify the systemic effects of TNCs.

This study takes an important step toward bridging this gap by analyzing a survey of TNC riders and drivers conducted by Strategic Vision Incorporated, consisting of a large sample $(\mathrm{N}=11,902)$ of the U.S. population residing in TNC-served areas. The survey included information on sociodemographic characteristics, personal attitudes toward adopting TNC services as a user or driver, and changes in travel mode and vehicle ownership preferences after using these services. Using this revealed preference data, we investigate the associations between sociodemographic characteristics and the following: a) preferences for being a rider, driver, or non-user of TNC services; b) ride-hailing users' propensity for ride-pooling; c) drivers' choices to switch to vehicles with better fuel economy; and d) drivers' decisions to buy, rent or lease a new vehicle, with driving for TNCs as a major contributing factor. We fit multinomial logistic regressions to answer the first question and binary logistic regressions to answer the remaining three. We also observe non-linear relationships by accounting for interaction effects of continuous covariates (e.g., age and income) with binary covariates (e.g., gender) while estimating preferences.

Results indicate that younger individuals who have higher levels of education, live in metropolitan areas, and belong to more affluent families are more likely to use ride-hailing services. However, the relationship between the individuals' probability of being a rider, driver or non-user of TNC services and their age is downward parabolic: it increases until the age of 44 and then decreases. Households 


\section{Summary}

that own more vehicles are less likely to be either riders or drivers. Exploring the inclination of the ridehailing users to ride-pool, we find that older travelers with higher household vehicle ownership who live in suburban areas are less likely to pool rides. In terms of interaction effects, females with an education level below postgraduation are more likely to ridepool than their male counterparts if they are younger than 34 years, but this pattern reverses if they are over 54.

Younger and married TNC drivers who drive daily and own a higher number of vehicles are more likely to switch to fuel-efficient vehicles, other things being equal. These results are consistent with previous studies eliciting preferences for electric vehicles. Further, interaction effect estimates reveal that postgraduate drivers who live in metropolitan areas view fuel efficient vehicles more favorably if they are aged below 48 years. Finally, younger and lower income drivers have a higher probability of considering driving for TNCs whilst purchasing a car. 


\section{Introduction}

his section summarizes literature relevant to individuals' preferences surrounding the use of transportation network company (TNC) services and the subsequent impacts on their mobility decisions. We first discuss the evolution of TNCs and proceed to describe the sociodemographic and geographic characteristics of individuals who have a higher tendency to use TNC services. We then review the literature on how these services are changing the landscape of urban travel patterns by affecting vehicle ownership preferences and demand for other travel modes. We conclude with a review of studies focusing on ride-hailing drivers, followed by highlighting the research gap that this study addresses.

\section{Evolution of TNC services}

In recent years, transportation has undergone an unprecedented transformation due to the rapid deployment of new technologies such as the internet and smartphones (Taylor et al. 2015). These advancements are the main drivers of the explosive growth of TNCs. As of 2016, ride-hailing services were active in almost 500 cities in the U.S. (Murphy 2016). However, a 2015 survey of 4,787 American adults by the Pew Research Center found that only $3 \%$ and $12 \%$ of TNC riders use these services on a daily or weekly basis, respectively (Smith 2016).

\section{Characteristics of TNC users}

Several correlation studies have identified characteristics of travelers with a higher propensity to use ride-hailing services. A survey conducted across seven major cities in the U.S. found that college-educated individuals adopt TNC services at almost twice the rate of those without a college degree (Clewlow and Mishra 2017). Furthermore, travelers younger than 29 years and older than 65 years were shown to be the most and least frequent users of ride-hailing services, respectively. Kooti et al. (2017) drew similar conclusions from data provided by Uber for 59 million rides and 4.1 million riders collected over seven months. The authors observed that younger riders are more likely to take frequent, shorter rides, while older travelers are more inclined toward infrequent, longer rides. In another study, Alemi et al. (2018) modeled individuals' lifestyles using the California Millennials Dataset to identify factors affecting the adoption of ride-hailing services. The results of this study indicated that highly educated, independent millennials who live in core urban areas without owning personal vehicles and who do not have children have the highest adoption rate. Individuals with variety-seeking and technologyembracing attitudes are more likely to use ride-hailing services.

Geographic context and built environment factors also play important roles in determining the usage frequency of ride-hailing. Clewlow and Mishra (2017) found that the adoption rate of these services is higher in urban areas (29\%) than in suburban ones (15\%). Alemi et al. (2018) also observed a positive association between the demand for TNC services and the urbanization of the neighborhood. Along the same lines, the Pew Research Center study found that users of these services most frequently live in urban ( $21 \%$ of respondents) or suburban (15\%) areas (Smith 2016). In a more recent study, Yu and Peng (2019) investigated the relationship between characteristics of the built environment and ride-hailing demand using 2016-2017 trip data from RideAustin, a local TNC company. The results support the findings of previous studies and also indicate that population density is a good predictor of ride-hailing demand. Moreover, areas with greater road and sidewalk densities are more likely to have a higher demand for TNC services. 


\section{Impact of TNCs on vehicle ownership and public transit ridership}

The availability of TNC services is likely to decrease household vehicle ownership, but the extent of the reduction is not clear. The American Public Transportation Association (2016) reported that ride-hailing users are more likely to own fewer cars. Similarly, Conway et al. (2018) used National Household Travel Survey data to examine the expansion of ride-hailing services within the U.S. and concluded that users are more likely to be multimodal, own fewer cars and use alternative modes of transportation. This is supported by a survey conducted in Austin, Texas by Hampshire et al. (2017), who found that $9 \%$ of ride-hailing users purchased a vehicle after a suspension of these services, and $45 \%$ of the TNC trips were replaced by driving.

The impact of TNC services on public transit is also unclear. Sadowsky and Nelson (2017) implemented a regression discontinuity design to measure the effect of TNCs on public transportation across 28 major U.S. cities. The authors found that the introduction of Uber led to an increase in the use of public transportation. However, the introduction of Lyft after a few months had a negative impact on the use of public transportation. They hypothesized that the competition between these TNCs led to a decrease in cost and wait time, causing more users to prefer these services to public transport. Dias et al. (2018) analyzed around one million trips by RideAustin and found that, although individuals living in neighborhoods with relatively poor access to public transit are more inclined to use ridehailing services, there is a synergy between public transport and ride-hailing in other areas. In another study, Barbar et al. (2017) used a difference-indifference design to quantify the impact of ride- hailing services and observed a significant decrease in road-based public transit services, especially in areas with poor public transport coverage, but an increase in the use of subways and commuter rail. Hall et al. (2018) also adopted a differencein-difference design and found that Uber is, on average, complementary to public transit; however, the impact on public transport ridership is positive in larger cities but negative in smaller ones.

\section{Preferences of TNC drivers}

Studies have touched upon driver safety (Feeney 2015), wages (Berger and Frey 2017), and sociodemographic characteristics of TNC drivers (Kooti 2017; Hall and Krueger 2018), as well as the willingness of individuals to become ride-hailing drivers (Berliner and Tal 2018). Hall and Kruger (2018) analyzed data from two surveys of Uber drivers in the U.S. that were conducted in December $2014(\mathrm{~N}=601)$ and November $2015(\mathrm{~N}=632)$. They found that $30 \%$ were aged between 30 and 39 , $47.7 \%$ had college or graduate degrees, and $14 \%$ were women. The authors also observed that more Uber drivers were single than married, and married drivers tended to have children. Berliner and Tal (2018) estimated the willingness of individuals to drive for TNCs using stated preference data collected in Irvine, California in 2015. They found that the desire to earn extra income and a fondness for driving were the two most common motivations among respondents willing to drive for ride-hailing services. Berliner and Tal also conclude that age, number of children, vehicle ownership, gender, and positive attitudes toward ride-hailing are significant predictors of a willingness to become a TNC driver.

\section{Research gaps and contributions}

This research builds upon prior studies on the preferences of riders and drivers for TNC services using revealed-preference, representative data for 
TNC-served areas in the U.S. First we expand the literature on understanding the socio-demographic characteristics of TNC riders and drivers. Second, we determine the demographic segments of TNC users that are most likely to be interested in ridepooling, which has received limited attention in the literature (Lavieri and Bhat, 2018). However, it is crucial to the timely and effective deployment of pooling services, which make TNCs more environmentally viable. Third, we identify TNC drivers with a high propensity to switch to fuelefficient cars, to further understand the impact of ride-hailing services on greenhouse gas emissions. Finally, we elicit preferences of TNC drivers to buy, rent or lease new vehicles with driving for TNCs as a major purchase consideration, a phenomenon that has not been explored in the existing literature. 


\section{Data and Summary Statistics}

\section{Data collection and weight computation}

We use data from a survey conducted by Strategic Vision Incorporated in 2017 of 11,902 ride-hailing riders, drivers, and non-users in TNC-served areas in the United States. Figure A1 in the Appendix shows the geographical distribution of the respondents across the contiguous 48 states. The survey data provides information on household characteristics and attitudes, as well as on ridehailing usage and preferences. The former includes age, gender, marital status, education level, household income, ethnicity, residential location, mode(s) of commuting, and household size.

The sample under- or over-represents some demographic groups. For example, women above the age of 49 living in metropolitan or urban areas with annual incomes under $\$ 100,000$ who use public or non-motorized transport are under-represented in the sample, while men above 54 living in small towns with annual incomes greater than $\$ 100,000$ are over-represented. To address this concern, we estimate person-level weights using the iterative proportional fitting (IPF) technique (Bergmann 2011). IPF matches the joint probability distribution of various demographic characteristics in the collected sample and the population-level datasets on urban and rural housing units (2016 American Community Survey data and 2010 U.S. Census Bureau data). In other words, we compute weights by scaling the survey sample proportions, in four demographic classes and 32 categories (four gender- and agebased, two income-based, two travel mode-based, and two residence location-based groups), relative to the corresponding class-specific proportions in the population-level data. We implement this IPF method using the 'ipfweight' package in Stata. The estimated weights vary between 0.15 and 4.65 . All results presented in this paper are based on this weighted sample.

\section{Explanatory and response variables}

Table 1 summarizes the statistics of the populationweighted explanatory variables used in all logistic regression models of this study. The sample statistics are consistent with those of the population.

Table 1. Key explanatory variables.

\begin{tabular}{lllllll} 
Explanatory variables & N & Mean & Median & SD & Min. & Max. \\
\hline Male indicator & 8,791 & 0.48 & 0 & 0.50 & 0 & 1 \\
\hline Single indicator & 8,791 & 0.35 & 0 & 0.48 & 0 & 1 \\
\hline Age (in years) & 8,791 & 46.77 & 47 & 15.73 & 18 & 100 \\
\hline Post-graduation indicator & 8,791 & 0.31 & 0 & 0.46 & 0 & 1 \\
\hline Annual income (\$) & 8,791 & 94,909 & 72,500 & 90,915 & 15,000 & $1,000,000$ \\
\hline Metropolitan resident indicator & 8,791 & 0.30 & 0 & 0.46 & 0 & 1 \\
\hline Household size 3+ indicator & 8,025 & 0.32 & 0 & 0.47 & 0 & 1 \\
\hline Total vehicle ownership & 8,791 & 2.15 & 2 & 1.17 & 0 & 6 \\
\hline Early adopter indicator & 8,791 & 0.19 & 0 & 0.39 & 0 & 1 \\
\hline Drive daily indicator & 1,541 & 0.25 & 0 & 0.43 & 0 & 1 \\
\hline
\end{tabular}

Source: KAPSARC. 
For example, in the weighted sample, the fraction of male respondents, average age, and average annual income are 48\%, 46.77 years and $\$ 94,909$, respectively; this compares with 49\%, 45.75 years and $\$ 81,346$ in the general population. Around 19\% of respondents are early adopters of these ridehailing services. Among 1,541 TNC drivers in the sample, around $25 \%$ drive daily.

Table 2 gives the key summary statistics of the response variables. The results indicate that the sample proportions of TNC riders, drivers, and non-users are $29 \%, 29 \%$, and $42 \%$, respectively. Among ride-hailing riders, $13 \%$ had used ride-pooling services. Among drivers, 53\% indicated that they would be inclined to shift toward more fuel-efficient vehicles, and $47 \%$ showed a high propensity toward buying, leasing or renting a new vehicle as a result of driving for TNCs.

\section{Mobility patterns of ride-hailing riders}

Table 3 depicts the association between the mobility option most used by respondents and their TNC usage frequencies. We label those who use TNCs at least once per week as 'frequent TNC users' and the remainder as 'infrequent TNC users.' The results suggest that for frequent TNC users, personal vehicles (53\%-61\%) and ride-hailing (22\%-32\%) are the two most used travel modes, followed by public transportation (4\%-10\%). For infrequent TNC users, personal vehicles $(79 \%-$ $87 \%$ ) are dominant, with few respondents using either public transit (3\%-6\%) or ride-hailing (3\%$5 \%$ ). We note a marginal increase in the share of public transit among the most used travel modes for frequent versus infrequent TNC users. These patterns indicate that ride-hailing replaces personal vehicle use but does not significantly impact public transport demand.

In Table 4, we analyze how the unavailability of one's preferred travel mode affects mobility patterns. Among those who normally favor ridehailing, $66 \%$ are likely to switch to driving personal vehicles and $14 \%$ to public transit, respectively. Hampshire et al. (2017) observed a similar trend: when ride-hailing services were suspended in

Table 2. Key response variables.

\begin{tabular}{llll} 
Response variables (indicators) & $\mathbf{N}$ & Mean & SD \\
\hline Model 1 & & & 0.45 \\
\hline TNC driver & 8,791 & 0.29 & 0.45 \\
\hline TNC user & 8,791 & 0.29 & 0.49 \\
\hline TNC non-user & 8,791 & 0.43 & 0.33 \\
\hline Model 2 & & & \\
\hline Ride-pooling user & 2,365 & 0.13 & \\
\hline Model 3 & & & \\
\hline TNC drivers who would prefer to switch to fuel-efficient vehicles & 1,533 & 0.53 & 0.50 \\
\hline Model 4 & & & \\
\hline $\begin{array}{l}\text { TNC drivers who considered driving for ride-hailing services while buying or } \\
\text { leasing a new vehicle }\end{array}$ & 1,540 & 0.47 & 0.50
\end{tabular}

Source: KAPSARC. 
Table 3. Most often used mobility options of the ride-hailing users $(N=11,902)$.

\begin{tabular}{|c|c|c|c|c|c|c|}
\hline \multirow{2}{*}{$\begin{array}{l}\text { Frequency of using ride-hailing } \\
\text { services or taxis }\end{array}$} & \multirow[t]{2}{*}{ User type } & \multicolumn{5}{|c|}{ What mobility options do you use most often? } \\
\hline & & Ride-hailing & $\begin{array}{l}\text { Driving } \\
\text { personal } \\
\text { vehicle }\end{array}$ & $\begin{array}{l}\text { Public } \\
\text { transit }\end{array}$ & Walk or bike & $\begin{array}{l}\text { Car } \\
\text { sharing or } \\
\text { car-pooling }\end{array}$ \\
\hline Once or more a day & \multirow{2}{*}{$\begin{array}{l}\text { Frequent TNC } \\
\text { users }\end{array}$} & $32 \%$ & $53 \%$ & $4 \%$ & $6 \%$ & $5 \%$ \\
\hline Once or more per week & & $22 \%$ & $61 \%$ & $10 \%$ & $5 \%$ & $2 \%$ \\
\hline $\begin{array}{l}\text { Once or more per month; once or more } \\
\text { in } 3 \text { months }\end{array}$ & \multirow{2}{*}{$\begin{array}{l}\text { Infrequent TNC } \\
\text { users }\end{array}$} & $5 \%$ & $79 \%$ & $6 \%$ & $6 \%$ & $3 \%$ \\
\hline $\begin{array}{l}\text { Once or more a year; once or more } \\
\text { every few years or never }\end{array}$ & & $3 \%$ & $87 \%$ & $3 \%$ & $5 \%$ & $2 \%$ \\
\hline
\end{tabular}

Source: KAPSARC.

Table 4. Mobility option most used in the absence of their current travel mode.

\begin{tabular}{|c|c|c|c|c|c|c|c|}
\hline \multirow{2}{*}{$\begin{array}{l}\text { Mobility option used most } \\
\text { often }\end{array}$} & \multicolumn{7}{|c|}{ How would you make your most frequent trip if your most frequently used option was not available? } \\
\hline & $\mathbf{N}$ & Ride-hailing & $\begin{array}{l}\text { Drive } \\
\text { personal } \\
\text { vehicle }\end{array}$ & $\begin{array}{l}\text { Public } \\
\text { transit }\end{array}$ & Walk or bike & $\begin{array}{l}\text { Car } \\
\text { sharing or } \\
\text { car-pooling }\end{array}$ & $\begin{array}{l}\text { Would not } \\
\text { make the trip }\end{array}$ \\
\hline Ride-hailing & 256 & $0 \%$ & $66 \%$ & $14 \%$ & $7 \%$ & $13 \%$ & $0 \%$ \\
\hline Drive personal vehicle & 6,369 & $31 \%$ & $0 \%$ & $9 \%$ & $8 \%$ & $46 \%$ & $6 \%$ \\
\hline Public transit & 243 & $29 \%$ & $43 \%$ & $0 \%$ & $17 \%$ & $4 \%$ & $2 \%$ \\
\hline Walk or bike & 372 & $12 \%$ & $60 \%$ & $17 \%$ & $0 \%$ & $6 \%$ & $5 \%$ \\
\hline Car sharing or car-pooling & 151 & $30 \%$ & $52 \%$ & $13 \%$ & $2 \%$ & $0 \%$ & $2 \%$ \\
\hline
\end{tabular}

Source: KAPSARC.

Austin, $41 \%$ of users switched to driving. For respondents who prefer to drive personal vehicles, $31 \%$ and $46 \%$ would shift to ride-hailing and carpooling/car-sharing, respectively, while those who most frequently use public transit mainly change to ride-hailing (29\%) and personal driving (43\%) rather than car-pooling/car-sharing (4\%). Although personal vehicle drivers and public transport users switch to ride-sharing at similar rates, the former accounts for $86 \%$ of the sample and therefore would have a much larger impact on ride-hailing demand.
The above findings strengthen our earlier conclusion that ride-sharing and car-sharing services are mainly capturing personal-driving demand, without substantially affecting the use of public transportation. This finding has implications for other countries, including Saudi Arabia, that, like the U.S., have high rates of personal vehicle usage and limited public transit options. Early evidence suggests that recent investments in Riyadh's transit infrastructure (Riyadh Development Authority 2019; Nanji 2018) are unlikely to be affected by the growth 
of TNC services. In contrast to Clewlow and Mishra (2017), we find evidence that TNC services do not induce travel demand-only $0.45 \%$ of frequent ride-hailing users would not have made their trips if these services were unavailable. These discrepancies can be attributed to different target samples in the two studies; in particular, the analysis by Clewlow and Mishra (2017) had an oversampling of respondents in San Francisco and Los Angeles.

We present other insightful statistics about ridehailing preferences. Around $10 \%$ of TNC users reported postponing the purchase of a new car. This result is similar to that of Hampshire et al. (2017) that $9 \%$ of the ride-hailing users purchased a vehicle after the suspension of TNC services in Austin. In terms of trip purpose, a high proportion $(46 \%)$ of respondents selected ride-hailing, carsharing or car-pooling as their preferred means of travel to and from social events. Furthermore, $21 \%$ of respondents chose "didn't want to drive after drinking" as their primary motivation for using ride-hailing services, making it the second most common reason behind "convenience" (24\%). These results align with studies that found these two factors to be the most prevalent motivations for preferring ride-hailing (Rayle et al. 2016; Alemi et al. 2018; Conway et al. 2018; Young and Farber 2019). They are also consistent with previous studies that found the most common ride-hailing trips are for recreational activities (Alemi et al. 2018; Lavieri and Bhat 2018; Young and Farber 2019).

We further analyze the $13 \%$ of ride-hailing users who have used ride-pooling services at least once. These respondents opted to ride-pool for slightly over a third $(34 \%)$ of their ride-hailing trips. Among the ride-hailing users that never used ride-pooling services, when asked for their reasons for not using ride-pooling services, half of them indicated that they had not heard of these services. Another dominant reason, chosen by $22 \%$, is a preference for "private rides."

\section{Preferences of non-users}

The leading reason, cited by $36 \%$ of non-users, for not utilizing TNC services is their preference for driving a personal vehicle. Another $21 \%$ of nonusers replied that they had never needed taxi or ride-hailing services. Non-users were also asked about utilizing TNC services for so-called 'last mile' travel-i.e., how to reach the nearest station for trips on public transportation. Approximately $41.3 \%$ reported their willingness to make this switch, suggesting that 'last mile' trips offer high potential to boost the adoption of TNC services among current non-users.

\section{Preferences of TNC drivers}

Drivers were asked about their level of satisfaction regarding working for TNCs. Most reported their experience to be excellent (54\%), followed by neutral (28\%) and unsatisfactory (18\%). As expected, TNC drivers who work more frequently drive more miles. Those working daily and every other day average 42 miles and 31 miles per week, respectively; those who work less than once per month drive an average of 16 miles per week.

Table 5 summarizes the relationship between the decision to rent/lease/purchase a vehicle and driving frequency. Among drivers who work daily, $65 \%$ indicated that driving for TNCs was a consideration when acquiring a new vehicle. As expected, this declines to $51 \%$ and $40 \%-46 \%$ for those who drive every other day and once a week or less, respectively. Moreover, $93 \%$ of drivers use their primary vehicles to drive for ride-hailing services, with little variation across different driving frequencies. 
Table 5. Decision to rent/lease/purchase car based on the frequency of driving for ride-hailing.

\begin{tabular}{llll}
$\begin{array}{l}\text { Frequency of driving for ride- } \\
\text { hailing services }\end{array}$ & $\begin{array}{l}\text { Number of } \\
\text { responses }\end{array}$ & $\begin{array}{l}\text { Was driving for ride-hailing service a consideration in your decision to rent/lease/ } \\
\text { purchase your primary vehicle? }\end{array}$ & No \\
\cline { 2 - 4 } & & Yes & $35 \%$ \\
\hline Daily & 478 & $65 \%$ & $49 \%$ \\
\hline Every other day & 343 & $51 \%$ & $57 \%$ \\
\hline Once in a week & 646 & $43 \%$ & $54 \%$ \\
\hline Once in a month & 298 & $46 \%$ & $60 \%$ \\
\hline Less than once per month & 353 & $40 \%$ & \\
\hline
\end{tabular}

Source: KAPSARC.

We then asked about the downtime activities of drivers, i.e., activities in-between rides. Around $29 \%$ reported that they drive to the busy parts of the city to get more rides, inducing extra vehicle miles traveled (VMT). Picking up passengers takes an average of nine and 10 minutes during peak and off-peak hours, respectively, and adds around
2-3 miles per trip. For future vehicle purchases, $26 \%$ of TNC drivers who work more than 20 hours per week would prefer diesel vehicles, due to their higher fuel economy, but this falls to $8 \%-11 \%$ among those who drive fewer hours. Around $25 \%$ would prefer to buy a hybrid electric vehicle. 


\section{Results and Discussion}

W

e report parameter estimates of the link function of the logit models and relative risk or odds-ratio estimates with $95 \%$ confidence intervals. We explore non-linear effects of continuous variables by plotting the predicted choice probabilities and marginal effect estimates over the support of the covariate. To compute these quantities at a given level of the covariate of interest, we fix all other covariates at their sample mean and make a unit change in the specific covariate of interest.

\section{Model 1-Preference for being a TNC rider or a driver}

Table 6 shows the parameter estimates and the relative risk ratios of the multinomial logistic model, which explain the association between individuals' sociodemographic characteristics and being a TNC rider, driver, or non-user.

The predicted choice probabilities and the marginal effect plots of age (see Appendix, Figure A2) indicate that the preference for being a TNC driver decreases, and being a non-user increases, with an increase in age, all else being equal. This result is consistent with the findings of Hall and Krueger (2018) who also observed a higher proportion of younger people among Uber drivers. Perhaps younger people find working through a platform such as Uber attractive because they value a flexible work schedule and are willing to take multiple part-time jobs. However, we observe a non-linear effect of age on the propensity of being a TNC user. The likelihood of being a user, compared to being a driver or non-user, increases with age for someone younger than 44 years, but the pattern is reversed for those over 44 years. Finally, the higher inclination of younger people to be TNC users or drivers aligns with the education and psychology studies that have established that younger people are more likely to adopt new information and communication technologies (Helsper and Eyon 2010; Milojev and Sibley 2017).

Higher income individuals are more inclined to use TNC services but have a lower propensity to become TNC drivers. These results are consistent across all income values (see Appendix, Figure A3) and align with previous studies (Rayes et al. 2014; Clewlow and Mishra 2017). A probable explanation is that wealthier individuals are more able to pay for TNC rides and value the convenience and time savings they offer. Similarly, they are less motivated to earn additional income by becoming TNC drivers. After controlling for key covariates including education, age, marital status, and gender, individuals with higher household vehicle ownership are less likely to use TNCs or become drivers. However, the variation in the predicted choice probabilities due to a change in vehicle ownership is very small (see Appendix, Figure A4). TNC services might serve as a convenient travel option rather than a frequent mode of transport for households with high vehicle ownership. Bhat and Lavieri (2018) found a decrease in ride-hailing frequency with the increase in vehicle availability.

Early adopters of technologies and residents of metropolitan areas are more inclined toward riding and driving ride-hailing services. In fact, magnitudes of relative risk ratios indicate that these two covariates have the most practically significant relationship to an individual's preference to ride or drive using TNC services.

Early adopters are 4.81 and 1.36 times more likely to be drivers and riders, respectively, compared to being non-users. For metropolitan area residents, these figures are 1.94 and 1.53 times for drivers and riders, respectively. 
These findings are consistent with the literature. Alemi et al. (2018) found that early adopters of TNC services are likely to be "technology-oriented" and thus tend to adopt such services in bundles as a part of their modern lifestyles. Similarly, Hall and Krueger (2018) and Alemi et al. (2018) observed a higher inclination among metropolitan residents toward using TNC services. Lavieri and Bhat (2018) speculated three possible reasons for this tendency: parking restrictions in urban areas, lower costs for ride-hailing trips due to shorter distances, and the higher reliability of TNC services compared with taxis and public transit. In addition, higher travel demand in metropolitan areas also explains residents' higher propensities to be drivers.

Finally, postgraduate degree holders and single individuals, everything else constant, are more likely to be TNC riders but less prone to be drivers. These results align with the findings of Lavieri and Bhat (2018).

\section{Model 2-Preference to ride-pool}

Table 7 shows the parameter estimates and odds ratios of a binary logistic model reflecting the preferences of TNC riders for ride-pooling (compared to the base category of non-users of ride-pooling). As the literature on ride-pooling is still at a nascent stage, we highlight some of the similarities between our results and the results of car-pooling/car-sharing studies, including new insights on the non-linear relationships between TNC rider preferences for ride-pooling and their gender and levels of education.

The predicted probability and marginal effect plots of age (see Appendix, Figure A5) indicate that proclivity to use ride-pooling is inversely related to the age of TNC users. Lavieri and Bhat (2018) observed a similar trend, which they attribute to tech-savviness and the variety-seeking behavior of younger people. Traditional car-pooling has also been found to be common among individuals aged between 25 and 55 (Shaheen et al. 2016). However, the relationship between age and propensity to ridepool varies with sociodemographic characteristics such as education level (Appendix, Figure A6) and gender (Appendix, Figure A7). The inclination of male and postgraduate TNC users to ride-pool is less affected by age than that of females and those with below postgraduate education, keeping all other characteristics the same. A young female TNC user is much more likely to ride-pool than a young male. More specifically, a female TNC user who is younger than 54 years has a higher probability of pooling than a male user of the same age, but the trend reverses for users older than 54 years. Riders with less than postgraduate education, and who are younger than 34 years, have a higher tendency to use ride-pooling than postgraduate TNC users of the same age, but the pattern is reversed for those older than 34 years.

We find that household vehicle ownership is negatively associated with ride-pooling: the odds of TNC riders opting to ride-pool decrease by a factor of 0.87 with the addition of a household vehicle. The predicted probability plot in the Appendix, Figure A8 shows the linear nature of this relationship. This is consistent with the findings of Lee et al. (2018) in their study on car-pooling.

Similar to the results of Model 1 above, metropolitan residents and early adopters of technology are more inclined to ride-pool, and males are less likely, all else being equal. A few studies in the environmental psychology literature (e.g., Glover et al. 1997) argue that females take a stronger stance on ethical, environmental and pro-social behavior compared to males; this may explain the higher proclivity of females to use ride-pooling services. Residential 
location is the most practically significant predictor: TNC users living in metropolitan areas are more likely to ride-pool by a factor of 1.73 compared to those living in suburban areas. This result is consistent with the findings of Almei et al. (2018) and Lavieri and Bhat (2018).

Table 6. Multinomial logistic parameter estimates and relative risk ratios (Model 1).

\begin{tabular}{|c|c|c|c|c|c|c|}
\hline \multirow[t]{2}{*}{ Explanatory variables } & \multicolumn{3}{|c|}{ Parameter estimates } & \multicolumn{3}{|c|}{ Relative risk ratios } \\
\hline & Estimate & Std. err. & z-stat & Estimate & LB $(95 \% \mathrm{Cl})$ & UB $(95 \% \mathrm{Cl})$ \\
\hline & \multicolumn{6}{|c|}{ Ride-hailing driver } \\
\hline Male indicator & -0.530 & 0.100 & -5.28 & 0.589 & 0.484 & 0.717 \\
\hline Single indicator & -0.026 & 0.121 & -0.22 & 0.974 & 0.769 & 1.234 \\
\hline Age & -0.134 & 0.005 & -27.76 & 0.875 & 0.866 & 0.883 \\
\hline Postgraduation indicator & -0.620 & 0.120 & -5.15 & 0.538 & 0.425 & 0.681 \\
\hline Annual income (US\$) & $-5.07 \mathrm{E}-06$ & $1.55 \mathrm{E}-06$ & -3.27 & 0.999995 & 0.999992 & 0.999998 \\
\hline Metropolitan resident indicator & 0.665 & 0.112 & 5.93 & 1.945 & 1.561 & 2.423 \\
\hline HH size 3+ indicator & 0.485 & 0.108 & 4.49 & 1.625 & 1.315 & 2.008 \\
\hline Total vehicle ownership & -0.116 & 0.049 & -2.38 & 0.890 & 0.809 & 0.980 \\
\hline Early adopter indicator & 1.571 & 0.117 & 13.46 & 4.813 & 3.828 & 6.050 \\
\hline \multirow[t]{2}{*}{ Constant } & 5.693 & 0.261 & 21.83 & & & \\
\hline & \multicolumn{6}{|c|}{ Ride-hailing user } \\
\hline Male indicator & -0.286 & 0.072 & -3.97 & 0.751 & 0.652 & 0.865 \\
\hline Single indicator & 0.292 & 0.092 & 3.17 & 1.339 & 1.118 & 1.604 \\
\hline Age & -0.045 & 0.003 & -15.70 & 0.956 & 0.950 & 0.961 \\
\hline Postgraduation indicator & 0.141 & 0.077 & 1.83 & 1.152 & 0.990 & 1.340 \\
\hline Annual income (US\$) & 7.35E-06 & 5.82E-07 & 12.63 & 1.000007 & 1.000006 & 1.000008 \\
\hline Metropolitan resident indicator & 0.425 & 0.088 & 4.83 & 1.529 & 1.287 & 1.817 \\
\hline HH size $3+$ indicator & -0.160 & 0.083 & -1.93 & 0.852 & 0.724 & 1.002 \\
\hline Total vehicle ownership & -0.086 & 0.035 & -2.47 & 0.918 & 0.857 & 0.982 \\
\hline Early adopter indicator & 0.309 & 0.109 & 2.83 & 1.362 & 1.100 & 1.687 \\
\hline Constant & 1.235 & 0.195 & 6.33 & & & \\
\hline $\mathrm{N}$ & 8,086 & & & & & \\
\hline Loglikelihood & -6109.5 & & & & & \\
\hline Pseudo R-square & 0.292 & & & & & \\
\hline
\end{tabular}

Note: "Ride-hailing non-user" is a base category. Std. err. = standard error; LB= lower bound; UB= upper bound; $\mathrm{Cl}=\mathrm{confidence} \mathrm{interval.}$

Source: KAPSARC. 
Table 7. Binary logistic parameter estimates and odds ratios (Model 2).

\begin{tabular}{|c|c|c|c|c|c|c|}
\hline \multirow[t]{2}{*}{ Explanatory variables } & \multicolumn{3}{|c|}{ Parameter estimates } & \multicolumn{3}{|c|}{ Odds ratio } \\
\hline & Estimate & Std. err. & z-stat & Estimate & LB $(95 \% \mathrm{Cl})$ & UB (95\% Cl) \\
\hline Male indicator & -1.341 & 0.635 & -2.11 & 0.262 & 0.075 & 0.908 \\
\hline Age & -0.047 & 0.014 & -3.43 & 0.955 & 0.929 & 0.980 \\
\hline Postgraduation indicator & -0.614 & 0.662 & -0.93 & 0.541 & 0.148 & 1.981 \\
\hline Metropolitan resident indicator & 0.550 & 0.165 & 3.34 & 1.733 & 1.255 & 2.393 \\
\hline Total vehicle ownership & -0.138 & 0.084 & -1.64 & 0.871 & 0.739 & 1.027 \\
\hline Early adopter indicator & 0.321 & 0.201 & 1.6 & 1.378 & 0.930 & 2.042 \\
\hline Male indicator $X$ age & 0.026 & 0.014 & 1.89 & 1.026 & 0.999 & 1.054 \\
\hline Postgrad indicator $X$ age & 0.016 & 0.014 & 1.13 & 1.016 & 0.988 & 1.045 \\
\hline Constant & 0.207 & 0.601 & 0.34 & & & \\
\hline$N$ & 2,504 & & & & & \\
\hline Loglikelihood & -853.9 & & & & & \\
\hline Pseudo R-square & 0.048 & & & & & \\
\hline
\end{tabular}

Note: "Ride-pooling non-user" is a base category and parameter estimates are for "Ride-pooling user." Std. err. = standard error; LB= lower bound; $\mathrm{UB}=$ upper bound; $\mathrm{Cl}=$ confidence interval.

Source: KAPSARC.

\section{Model 3-Preferences of TNC drivers for fuel-efficient vehicles}

Table 8 summarizes the results of a binary logistic model that identifies the characteristics of TNC drivers who would prefer to switch to fuel-efficient vehicles (compared to the base category of drivers who prefer not to switch to fuel-efficient vehicles). Since there is no previous study on such preferences of TNC drivers, we highlight some similarities and differences between our results and those of studies concerned with the characteristics of electric vehicle (EV) buyers.

The predicted probability plot shows a negative correlation between the ages of TNC drivers and their propensity to switch to fuel-efficient vehicles (see Appendix, Figure A9). Hidrue et al. (2011) observe a similar trend among EV buyers. The relationships between the inclination of drivers to switch to fuel-efficient vehicles and their residential locations (see Appendix, Figure A10), education levels (see Appendix, Figure A11), and marital status (see Appendix, Figure A12) vary across driver ages.

We find that postgraduate education and metropolitan residency are the two most significant predictors of propensities to switch to more fuelefficient vehicles. Drivers with postgraduate education who live in metropolitan areas are more prone than their counterparts to make this change if their age is below 48 years, all else being equal, 
although this pattern reverses for postgraduate drivers older than 48 years. These results are consistent with the previous studies showing that younger and more highly educated individuals are more prone to buy alternative fuel vehicles (Dütschke et al. 2013; Hackbarth and Madlener 2013). Individuals with higher levels of education tend to have a greater awareness of the fuel-saving benefits and lower environmental impacts from improved fuel economy. Additionally, hybrid electric vehicles are more suited to improving fuel-savings in the stop-and-go traffic conditions of congested metropolitan areas (Romm and Frank 2006).

Married drivers are more inclined to switch to fuelefficient vehicles than their single counterparts among drivers below 60 years of age. These results are consistent with those of Peter et al. (2011), who found that households with children are more likely to be EV buyers. In the context of this study, married drivers might be more conscious about fuel-efficiency because they may need to drive their vehicles more than their single counterparts do for other household activities. A recent report by Ipsos (2017) also shows that married households are more inclined toward buying electric vehicles.

Drivers who are early adopters of technologies have greater odds of switching to a fuel-efficient vehicle by a factor of 1.47 . This observation makes intuitive sense because early adopters are likely to have a greater affinity toward technology. The results of a survey conducted by CleanTechnica are also consistent with our findings that $38 \%$ of drivers surveyed selected "love for new technology" as the reason for switching to the fuel-efficient vehicles.

TNC drivers who drive daily are also more inclined toward fuel-efficient vehicles than those who drive less frequently. Daily drivers are likely more sensitive to fuel prices due to more frequent driving and higher VMT. It is well established in EV literature that early adopters of EVs accumulate more VMT (Plotz et al. 2014). Hidrue et al. (2011) have shown that an individual's willingness to pay a premium for an EV is primarily driven by savings in fuel costs, which is further associated with VMT.

Drivers from households that own more vehicles also have a higher tendency to switch to fuelefficient vehicles. The probability of switching increases linearly with the increase in the number of vehicles (see Appendix, Figure A13). Since the income of drivers is not controlled in the specification (because it was not statistically significant), perhaps the missing income effect is also reinforcing the pro-fuel-efficiency behavior of drivers with higher vehicle ownership. We observe similar relationships in EV literature. Previous studies have shown that higher-income consumers are more likely to buy EVs (Erdem et al. 2010; Saarenpää et al. 2013). Moreover, EVs are typically owned by high-income households with more than one car (Hjorthol 2013).

Table 8. Binary logistic parameter estimates and odds ratios (Model 3).

\begin{tabular}{|c|c|c|c|c|c|c|}
\hline \multirow[t]{2}{*}{ Explanatory variables } & \multicolumn{3}{|c|}{ Parameter estimates } & \multicolumn{3}{|c|}{ Odds ratio } \\
\hline & Estimate & Std. err. & z-stat & Estimate & LB $(95 \% \mathrm{Cl})$ & UB $(95 \% \mathrm{Cl})$ \\
\hline Drive daily indicator & 0.346 & 0.147 & 2.35 & 1.413 & 1.059 & 1.887 \\
\hline Single indicator & -1.026 & 0.431 & -2.38 & 0.359 & 0.154 & 0.834 \\
\hline Age & -0.015 & 0.009 & -1.64 & 0.985 & 0.967 & 1.003 \\
\hline
\end{tabular}




\begin{tabular}{lllllll} 
Explanatory variables & \multicolumn{3}{l}{ Parameter estimates } & \multicolumn{2}{l}{ Odds ratio } \\
\cline { 2 - 7 } & Estimate & Std. err. & z-stat & Estimate & LB (95\% Cl) & UB (95\% Cl) \\
\hline Postgrad indicator & 1.447 & 0.573 & 2.53 & 4.250 & 1.384 & 13.054 \\
\hline Metropolitan resident indicator & 1.392 & 0.441 & 3.16 & 4.024 & 1.695 & 9.554 \\
\hline Total vehicle ownership & 0.054 & 0.055 & 0.97 & 1.055 & 0.947 & 1.176 \\
\hline Early adopter indicator & 0.385 & 0.129 & 2.98 & 1.470 & 1.140 & 1.895 \\
\hline Single indicator X age & 0.016 & 0.013 & 1.3 & 1.017 & 0.992 & 1.042 \\
\hline Postgrad indicator X age & -0.032 & 0.016 & -2.02 & 0.969 & 0.940 & 0.999 \\
\hline Metropolitan resident indicator X age & -0.032 & 0.013 & -2.5 & 0.969 & 0.945 & 0.993 \\
\hline
\end{tabular}

\begin{tabular}{ll}
\hline $\mathrm{N}$ & 1,534 \\
\hline Loglikelihood & -994.3 \\
\hline Pseudo R-square & 0.06 \\
\hline
\end{tabular}

Note: "No preference of ride-hailing drivers to switch to fuel efficient vehicles" is a base category and parameters are estimated for "Preference for ride-hailing..." LB $(95 \% \mathrm{Cl})$ and UB $(95 \% \mathrm{Cl})$ imply lower and upper bounds of a 95\% confidence interval. Std. err. = standard error; $\mathrm{LB}=$ lower bound; $\mathrm{UB}=$ upper bound; $\mathrm{Cl}=$ confidence interval.

\section{Model 4-Preference of TNC drivers to buy a new vehicle}

We use a binary logistic regression to estimate whether driving for a ride-hailing service was a consideration in TNC drivers' decisions to buy, rent or lease a new vehicle. Results are shown in Table 9 (compared to the base category of no change in the preference to buy a new vehicle as a result of driving for TNCs).

The predicted probability and marginal effect plots (in Appendix, Figure A14) indicate that the tendency for driving for TNCs to be a major consideration when buying a new vehicle is inversely related to the age of the TNC driver, keeping everything else constant. Among drivers below 55 years of age, those with postgraduate education and who are married have a higher propensity than their counterparts to buy a car to drive for TNCs, but these patterns reverse for older drivers (see Appendix, figures $\mathrm{A} 15$ and $\mathrm{A16}$ ) as the negative effect of the increase in age on the probability of buying a car to drive for TNCs becomes much higher.

Higher income drivers have a lower inclination to buy vehicles with driving for TNCs as a consideration (see the predicated probability and marginal effect in Appendix, Figure A17). Further investigation of this income effect in single and married drivers indicates that the increase in income of married drivers increases their probability of buying cars to drive for TNCs, but the reverse is seen for single drivers (see Appendix, Figure A18). The combined negative income effect is a manifestation of the steeper rate of decline in the probability for single drivers as compared to the rate of increase for married drivers. For example, for single and married drivers with annual incomes 
below $\$ 10,000$ the predicted probability is the same (around 0.48), but at $\$ 100,000$ income it increases to 0.51 for married drivers and falls to 0.38 for single ones, keeping all other characteristics the same. The high propensity of low-income single drivers to buy, rent or lease a vehicle with driving for TNCs being a major consideration in part explains why some TNCs offer renting and leasing services to attract drivers from this demographic group.

Male drivers residing in metropolitan areas, who are early adopters, have higher vehicle ownership and drive daily, have a higher inclination to buy vehicles with driving for TNCs being a major purchase consideration than those with the opposite profile, all else being equal. In terms of the strength of these relationships, being an early adopter of technologies increases the odds by a factor of 2.59 , driving daily by a factor of 2.09 , and metropolitan residency by a factor of 1.90 .

Table 9. Binary logistic parameter estimates and odds ratios (Model 4).

\begin{tabular}{|c|c|c|c|c|c|c|}
\hline \multirow[t]{2}{*}{ Explanatory variables } & \multicolumn{3}{|c|}{ Parameter estimates } & \multicolumn{3}{|c|}{ Odds ratio } \\
\hline & Estimate & Std. err. & z-stat & Estimate & LB (95\% CI) & UB $(95 \% \mathrm{CI})$ \\
\hline Drive daily indicator & 0.736 & 0.159 & 4.620 & 2.09 & 1.53 & 2.85 \\
\hline Male indicator & 0.459 & 0.120 & 3.840 & 1.58 & 1.25 & 2.00 \\
\hline Single indicator & -0.518 & 0.529 & -0.980 & 0.60 & 0.21 & 1.68 \\
\hline Age & -0.032 & 0.010 & -3.150 & 0.97 & 0.95 & 0.99 \\
\hline Postgraduation indicator & 1.122 & 0.588 & 1.910 & 3.07 & 0.97 & 9.72 \\
\hline Annual income (US\$) & 1.17E-06 & $6.18 \mathrm{E}-07$ & 1.900 & 1.000001 & 1 & 1.000002 \\
\hline Metropolitan resident indicator & 0.639 & 0.138 & 4.620 & 1.90 & 1.44 & 2.49 \\
\hline Total vehicle ownership & 0.163 & 0.056 & 2.920 & 1.18 & 1.05 & 1.31 \\
\hline Early adopter indicator & 0.953 & 0.135 & 7.060 & 2.59 & 1.99 & 3.38 \\
\hline Single indicator $X$ age & 0.020 & 0.016 & 1.250 & 1.02 & 0.99 & 1.05 \\
\hline Postgrad indicator $\mathrm{X}$ age & -0.024 & 0.017 & -1.400 & 0.98 & 0.95 & 1.01 \\
\hline Single indicator $X$ annual income & $-5.64 \mathrm{E}-06$ & $2.42 \mathrm{E}-06$ & -2.330 & 0.999994 & 0.999990 & 0.999999 \\
\hline Constant & -0.699 & 0.376 & -1.860 & & & \\
\hline
\end{tabular}

\begin{tabular}{ll}
\hline $\mathrm{N}$ & 1,539 \\
\hline Loglikelihood & -914.5 \\
\hline Pseudo R-square & 0.139 \\
\hline
\end{tabular}

Note: "No change in preference to buy a new vehicle due to being a ride-hailing driver" is a base category and parameters are estimated for "change in preference..." LB $(95 \% \mathrm{Cl})$ and UB $(95 \% \mathrm{Cl})$ imply lower and upper bounds of a $95 \%$ confidence interval. Std. err. = standard error; $\mathrm{LB}=$ lower bound; $\mathrm{UB}=$ upper bound; $\mathrm{Cl}=$ confidence interval. 


\section{Concluding Remarks and Implications for Stakeholders}

Whis research provides new insights into behaviors related to TNC services by identifying the relationship between individuals' sociodemographic characteristics and their preferences to use ride-hailing services (as riders or drivers) and willingness to ride-pool. The analysis uses calibrated multinomial and binary logistic models based on a dataset taken from a 2017 survey $(\mathrm{N}=11,902)$ in TNC-served U.S. cities.

We make a unique contribution to ride-hailing literature by estimating the proclivity of TNC drivers to buy new vehicles with the consideration of driving for TNCs and shifting to fuel-efficient vehicles as influencing factors, neither of which have been explored in the existing literature. We also observe non-linear relationships by accounting for the interaction effects of continuous covariates (e.g., age and income) with binary covariates (e.g., gender) while estimating preferences.

The findings from this study can inform key stakeholders (such as transportation planners, government agencies, automakers, and TNCs) as they develop policies to encourage ride-pooling and the deployment of high fuel economy vehicles, leading to systemic environmental benefits. For instance, automotive manufacturers and autoleasing companies could partner with TNCs to offer leasing plans for high fuel efficiency and electric vehicles to the identified pro-fuel-efficiency drivers. This would not only benefit drivers by reducing their operating costs but would also help automakers meet zero emission vehicle requirements and federal fleet fuel economy targets. The lease options offered to Uber and Lyft drivers by General Motors on its all-electric Chevrolet Bolt is a case-in-point (Kurczewski 2017). In addition, the deployment of a higher number of fuel-efficient vehicles would help TNCs to balance supply and demand for their new environmentally friendly initiatives, such as Lyft's 'green mode' (Price 2019), which allow riders to specifically call 'green' vehicles.

Targeted campaigns could be organized to spread awareness of ride-pooling services and their environmental benefits to the ride-hailing users identified as having a high propensity to ride-pool. Our research showed that younger female passengers, who are known to be more environmentally conscious, prefer ride-pooling. To ensure passenger safety while pooling, automakers could be encouraged to provide tailor-made vehicles for pooling that include partitions.

It is important to note that this study explores correlation patterns only: readers should not interpret the results as identifying causal relationships between individuals' sociodemographic characteristics and their preferences. Collaborations with TNCs to conduct randomized experiments in order to disentangle causal effects is a potential avenue for future research. 


\section{References}

Alemi, Farzad, Giovanni Circella, Susan Handy, and Patricia Mokhtarian. 2018. "What Influences Travelers to Use Uber? Exploring the Factors Affecting the Adoption of On-demand Ride Services in California." Travel Behaviour and Society 13: 88-104. https://doi. org/10.1016/j.tbs.2018.06.002

Babar, Yash, and Gordon Burtch. 2017. "Examining the Heterogeneous Impact of Ridehailing Services on Public Transit Use." Minnesota: Carlson School of Management, University of Minnesota. Available at SSRN 3042805. https://papers.ssrn.com/sol3/papers. cfm?abstract_id=3042805

Bergmann, Michael. 2011. "ipfweight: Stata Module to Create Adjustment Weights for Surveys." Statistical Software Components S457353. Department of Economics, Boston College. http://econpapers.repec.org/software/ bocbocode/s457353.htm

Berliner, Rosaria M., and Gil Tal. 2018. "What Drives Your Drivers: An In-Depth Look at Lyft and Uber Drivers." January. Davis, California: Institute of Transportation Studies, University of California. https://itspubs.ucdavis. edu/wp-content/themes/ucdavis/pubs/download_pdf. php?id=2851

CleanTechnica. 2016. "Electric Car Drivers: Desires, Demands \& Who They Are." Accessed March 25, 2019. https://cleantechnica.com/files/2017/05/Electric-Car-Drivers-Report-Surveys-CleanTechnica-Free-Report.pdf

Clewlow, Regina R., and Gouri S. Mishra. 2017. "Disruptive Transportation: The Adoption, Utilization, and Impacts of Ride-hailing in the United States." Davis, California: Institute of Transportation Studies, University of California. https://itspubs.ucdavis.edu/wp-content/ themes/ucdavis/pubs/download_pdf.php?id=2752

Conway, Matthew, Deborah Salon, and David King. 2018. "Trends in Taxi Use and the Advent of Ridehailing, 1995-2017: Evidence from the US National Household Travel Survey." Urban Science 2(3): 79. https://www.mdpi. com/2413-8851/2/3/79

Dias, Felipe F., Patrícia S. Lavieri, Taehooie Kim, Chandra R. Bhat, and Ram M. Pendyala.2019. "Fusing Multiple Sources of Data to Understand Ride-Hailing Use." Transportation Research Record no. 2673 (6):214224. https://doi.org/10.1177/0361198119841031
Dütschke, Elisabeth, Uta Schneider, and Anja Peters. 2013. "Who Will Use Electric Vehicles?" Working Paper Sustainability and Innovation (6). Fraunhofer Institute for Systems and Innovation Research. https://www.isi.fraunhofer.de/content/dam/isi/dokumente/sustainability-innovation/2013/WP06-2013_Electric_Vehicles.pdf

Erdem, Cumhur, İsmail Şentürk, and Türker Şimşek. 2010. "Identifying the Factors Affecting the Willingness to Pay for Fuel-efficient Vehicles in Turkey: a Case of Hybrids." Energy Policy 38(6): 3038-3043. https://doi. org/10.1016/j.enpol.2010.01.043

Franzen, Axel, and Dominikus Vogl. 2013. "Two Decades of Measuring Environmental Attitudes: A Comparative Analysis of 33 Countries." Global Environmental Change 23(5): 1001-1008. https://doi.org/10.1016/j. gloenvcha.2013.03.009

Greenblatt, Jeffery B., and Susan Shaheen. 2015. "Automated Vehicles, On-demand Mobility, and Environmental Impacts." Current Sustainable/Renewable Energy Reports 2(3):74-81. https://doi.org/10.1007/ s40518-015-0038-5

Glover, Saundra H., Minnette A. Bumpus, John E. Logan, and James R. Ciesla. 1997. "Re-examining the Influence of Individual Values on Ethical Decision Making." In From the Universities to the Marketplace: The Business Ethics Journey, 109-119. Springer, Dordrecht.

Hall, Jonathan D., Craig Palsson, and Joseph Price. 2018. "Is Uber a Substitute or Complement for Public Transit?" Journal of Urban Economics 108:36-50. https:// doi.org/10.1016/j.jue.2018.09.003

Hall, J. V., and A. B. Krueger. 2018. An Analysis of the Labor Market for Uber's Driver-partners in the U.S." Industrial and Labor Relations Review 71(3): 705-732. https://doi.org/10.1177/0019793917717222

Hackbarth, André, and Reinhard Madlener. 2013.

"Consumer Preferences for Alternative Fuel Vehicles: A Discrete Choice Analysis." Transportation Research Part D: Transport and Environment 25:5-17. https://doi. org/10.1016/j.trd.2013.07.002

Hampshire, Robert, Chris Simek, Tayo Fabusuyi, Xuan $\mathrm{Di}$, and $\mathrm{Xi}$ Chen. 2017. "Measuring the Impact of an Unanticipated Disruption of Uber/Lyft in Austin, TX." Available at SSRN: https://ssrn.com/abstract=2977969 or http://dx.doi.org/10.2139/ssrn.2977969 
Hawkins, Andrew. 2018. "Uber Express Pool Offers the Cheapest Fares Yet in Exchange for a Little Walking." The Verge, February 21. Accessed April 4, 2019. https://www.theverge.com/2018/2/21/17020484/ uber-express-pool-launch-cities.

Helsper, Ellen Johanna, and Rebecca Eynon. 2010. "Digital Natives: Where is the Evidence?" British Educational Research Journal 36(3): 503-520. https://doi. org/10.1080/01411920902989227

Hidrue, Michael K., George R. Parsons, Willett Kempton, and Meryl P. Gardner. 2011. "Willingness to Pay for Electric Vehicles and their Attributes." Resource and Energy Economics 33(3): 686-705. https://doi.org/10.1016/j. reseneeco.2011.02.002

Hjorthol, Randi. 2013. "Attitudes, Ownership and Use of Electric Vehicles-A Review of Literature." Institute of Transport Economics, Norwegian Centre for Transport Research. Oslo. https://www.toi.no/publications/ attitudes-ownership-and-use-of-electric-vehicles-a-review-of-literature-article31833-29.html

Ipsos. 2017. "Is There a Target Market for Electric Vehicles?" Accessed February 20, 2019. https://www. ipsos.com/sites/default/files/2017-04/ipsos-marketing-target-market-electric-vehicles.PD__0.pdf.

Kooti, Farshad, Mihajlo Grbovic, Luca Maria Aiello, Nemanja Djuric, Vladan Radosavljevic, and Kristina Lerman. 2017. "Analyzing Uber's Ride-sharing Economy." April. In Proceedings of the 26th International Conference on World Wide Web Companion, 574-582. International World Wide Web Conferences Steering Committee. https://doi.org/10.1145/3041021.3054194

König, Alexandra, Tabea Bonus, and Jan Grippenkoven. 2018. "Analyzing Urban Residents' Appraisal of Ridepooling Service Attributes with Conjoint Analysis." Sustainability 10(10): 3711. https://doi.org/10.3390/ su10103711

Kurczewski, Nick. 2017. "GM Announces Bolt Lease for Uber, Lyft Drivers." Accessed April 10, 2019. https://www. cars.com/articles/gm-announces-bolt-lease-for-uber-lyftdrivers-1420695330355

Lee, Jae Hyun, and Konstadinos G. Goulias. 2018. "A Decade of Dynamics of Residential Location, Car Ownership, Activity, Travel and Land Use in the Seattle Metropolitan Region." Transportation Research Part A: Policy and Practice 114B: 272-287. https://doi.org/10.1016/j. tra.2018.01.029
Lavieri, Patrícia S., Chandra R. Bhat. 2018. "MaaS in Car-Dominated Cities: Modeling the Adoption,

Frequency, and Characteristics of Ride-hailing Trips in Dallas, Texas." Department of Civil, Architectural and Environmental Engineering, The University of Texas at Austin.

Martin, Elliot W., and Susan A. Shaheen. 2011. Greenhouse Gas Emission Impacts of Carsharing in North America. Transactions on Intelligent Transportation Systems 12(4): 1074-1086. The Institute of Electrical and Electronics Engineers. https://doi.org/10.1109/ TITS.2011.2158539

Milojev, Petar, and Chris G. Sibley. 2017. "Normative Personality Trait Development in Adulthood: A 6-year Cohort-sequential Growth Model." Journal of Personality and Social Psychology 112(3): 510.

Feigon, Sharon, and Colin Murphy. 2016. "Shared Mobility and the Transformation of Public Transit." Chicago: American Public Transportation Association. https://www. apta.com/wp-content/uploads/Resources/resources/ reportsandpublications/Documents/APTA-Shared-Mobility.pdf

Nanji, Noor. 2018. "Riyadh Metro Mega-project to be Fully Operational by 2021." The National, March 8. https://www. thenational.ae/business/travel-and-tourism/riyadh-metro-mega-project-to-be-fully-operational-by-2021-1.711522

Neoh, Jun Guan, Maxwell Chipulu, and Alasdair Marshall. 2017. "What Encourages People to Carpool? An Evaluation of Factors with Meta-analysis." Transportation 44(2): 423-447. https://doi.org/10.1007/s11116-015-9661-7

Peters, Anja, Raphael Agosti, Mareike Popp, and Bettina Ryf. 2011. "Electric Mobility: A Survey of Different Consumer Groups in Germany with Regard to Adoption." Summer Study Proceedings Series, European Council for an Energy Efficient Economy. https:// www.eceee.org/library/conference_proceedings/ eceee_Summer_Studies/2011/4-transport-and-mobility-how-to-deliver-energy-efficiency $160 /$ electric-mobility-a-survey-of-different-consumer-groups-in-germany-with-regard-to-adoption/

Plötz, Patrick, Uta Schneider, Joachim Globisch, and Elisabeth Dütschke. 2014. "Who Will Buy Electric Vehicles? Identifying Early Adopters in Germany." Transportation Research Part A: Policy and Practice 67: 96-109. https://doi.org/10.1016/j.tra.2014.06.006 
Price, Emily. 2019. "Lyft Will Allows Riders to Request an EV Via a New 'Green Mode'." Fortune, February 26. Accessed on April 10, 2019. http://fortune. com/2019/02/06/lyft-will-allows-riders-to-request-an-evvia-a-new-green-mode

Rayle, Lisa, Susan A. Shaheen, Nelson Chan, Danielle Dai, and Robert Cervero. 2014. "App-based, On-demand Ride Services: Comparing Taxi and Ridesourcing Trips and User Characteristics in San Francisco." University of California, Berkeley Transportation Center. https:// www.its.dot.gov/itspac/dec2014/ridesourcingwhitepaper_nov2014.pdf

Riyadh Development Authority. 2019. "King Abdulaziz Project for Riyadh Public Transport." http://www.ada.gov. sa/ADA_e/DocumentShow_e/?url=/res/ADA/En/Projects/ RiyadhMetro/index.html

Romm, Joseph J., and Andrew A. Frank. 2006. "Hybrid Vehicles Gain Traction." Scientific American 294(4): 72-79.

Saarenpää, Jukka, Mikko Kolehmainen, and Harri Niska. 2013. "Geodemographic Analysis and Estimation of Early Plug-in Hybrid Electric Vehicle Adoption." Applied Energy 107: 456-464. https://doi.org/10.1016/j. apenergy.2013.02.066

Schaller, Bruce. 2018. "The New Automobility: Lyft, Uber and the Future of American Cities." Accessed March 1, 2019. http://www.schallerconsult.com/rideservices/automobility.pdf

Shaheen, Susan, and Nelson Chan. 2016. "Mobility and the Sharing Economy: Potential to Facilitate the First- and Last-mile Public Transit Connections." Built Environment 42(4): 573-588.
Shaheen, Susan A., Nelson D. Chan, and Teresa Gaynor. 2016. "Casual carpooling in the San Francisco Bay Area: Understanding user characteristics, behaviors, and motivations." Transport Policy 51: 165-173. https://doi. org/10.1016/j.tranpol.2016.01.003

Smith, Aaron. 2016. "Shared, Collaborative and on Demand: The New Digital Economy." May 19, Pew Research Center. https://www.pewresearch.org/ internet/2016/05/19/the-new-digital-economy/

Sadowsky, Nicole, and Erik Nelson. 2017. "The Impact of Ride-hailing Services on Public Transportation Use: A Discontinuity Regression Analysis." Economics Department Working Paper Series 13. Bowdoin College. https://digitalcommons.bowdoin.edu/econpapers/13

Taylor, Brian D., Ryan Chin, Melanie Crotty, Jennifer Dill, Lester A Hoel, Michael Manville, Steve Polzin, Bruce Schaller, Susan Shaheen and Dan Sperling. 2016. "Between Public and Private Mobility: Examining the Rise of Technology-Enabled Transportation Services."

Transportation Research Board Special Report 319.

Washington: The National Academies Press. https://doi. org/10.17226/21875

Yu, Haitao, and Zhong-Ren Peng. 2019. "Exploring the spatial variation of ridesourcing demand and its relationship to built environment and socioeconomic factors with the geographically weighted Poisson regression." Journal of Transport Geography. 75: 147-163. https://doi. org/10.1016/j.jtrangeo.2019.01.004 


\section{Appendix 1: Figures}

Figure A1. Geographical distribution of respondents at state-level $(\mathrm{N}=11,902)$.

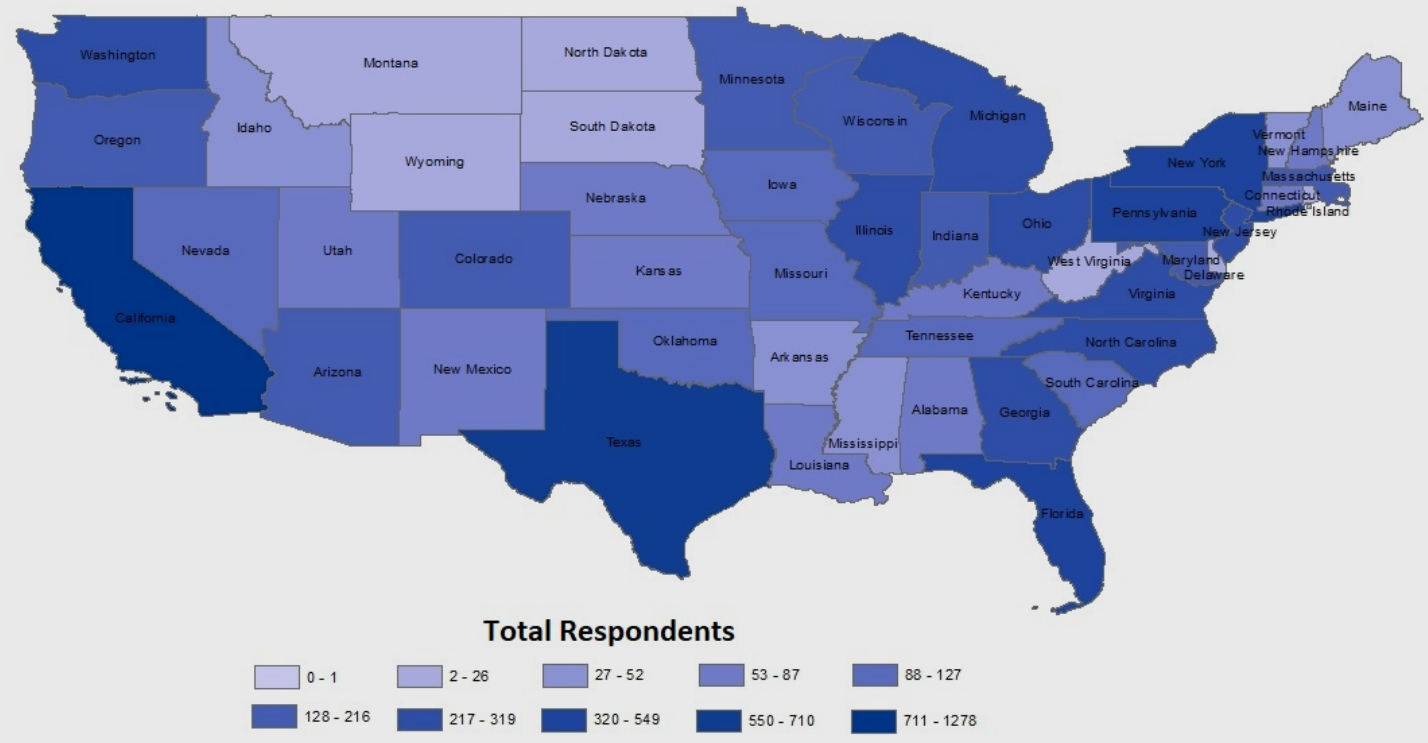

Source: KAPSARC.

Figure A2. Predicted probability and the marginal effect of age (Model 1).
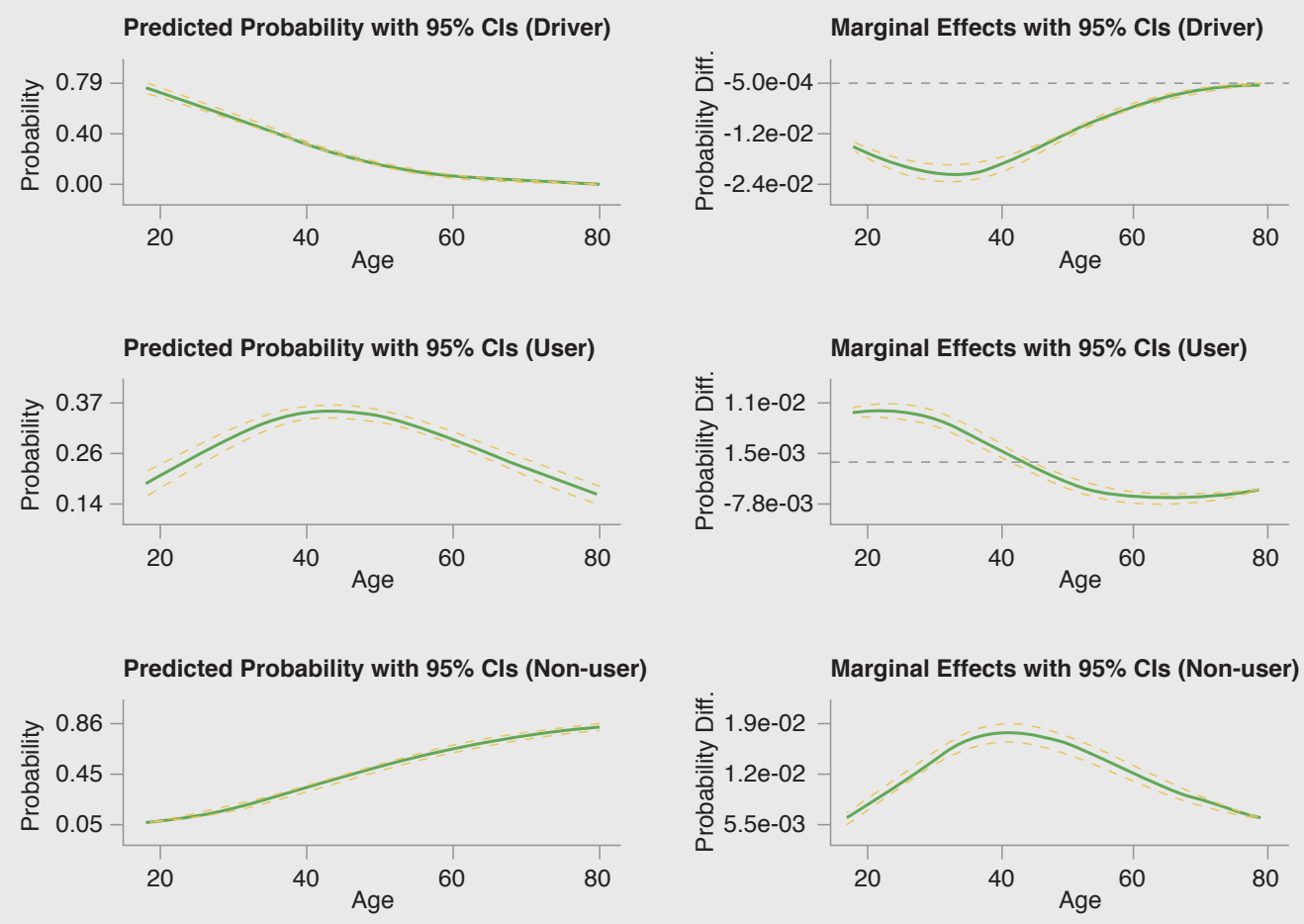

Source: KAPSARC. 
Figure A3. Predicted probability and the marginal effect of income (Model 1).
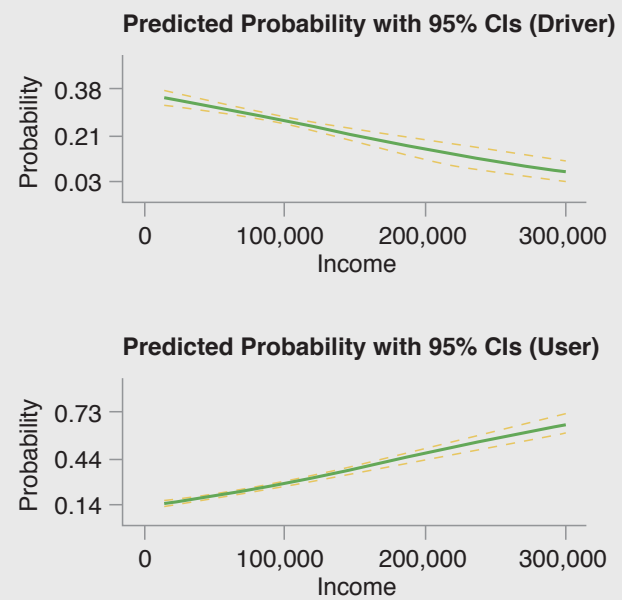

Predicted Probability with $95 \%$ Cls (Non-user)

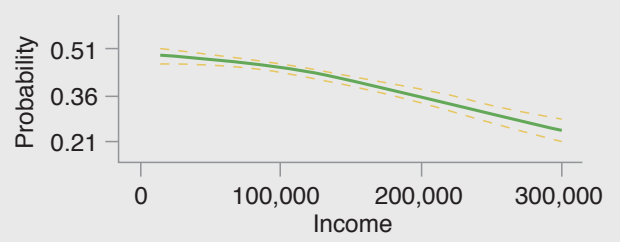

Marginal Effects with 95\% Cls (Driver)

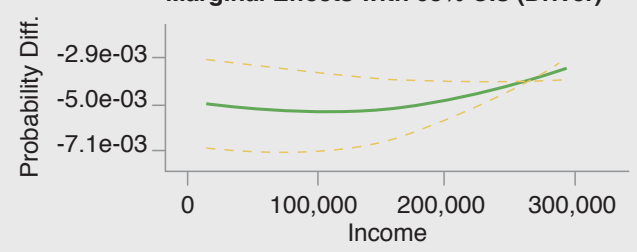

Marginal Effects with $95 \%$ Cls (User)

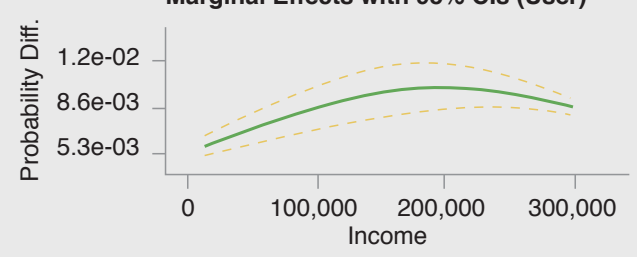

Marginal Effects with 95\% Cls (Non-user)

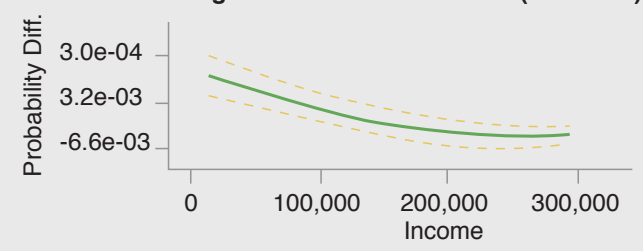

Source: KAPSARC.

Figure A4. Predicted probability and the marginal effect of total vehicle ownership (Model 1).

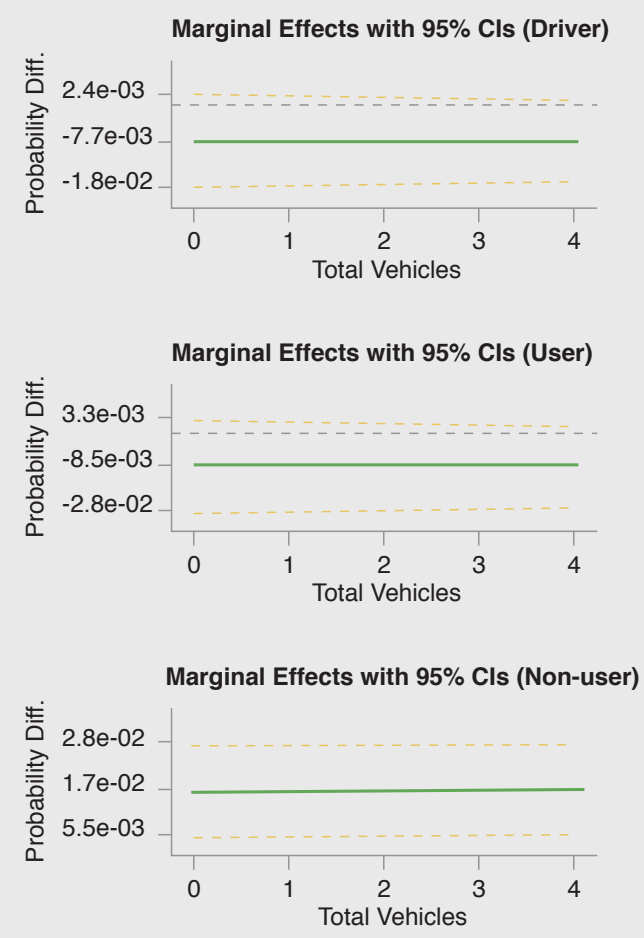

Source: KAPSARC. 
Figure A5. Predicted probability and the marginal effect of age (Model 2).
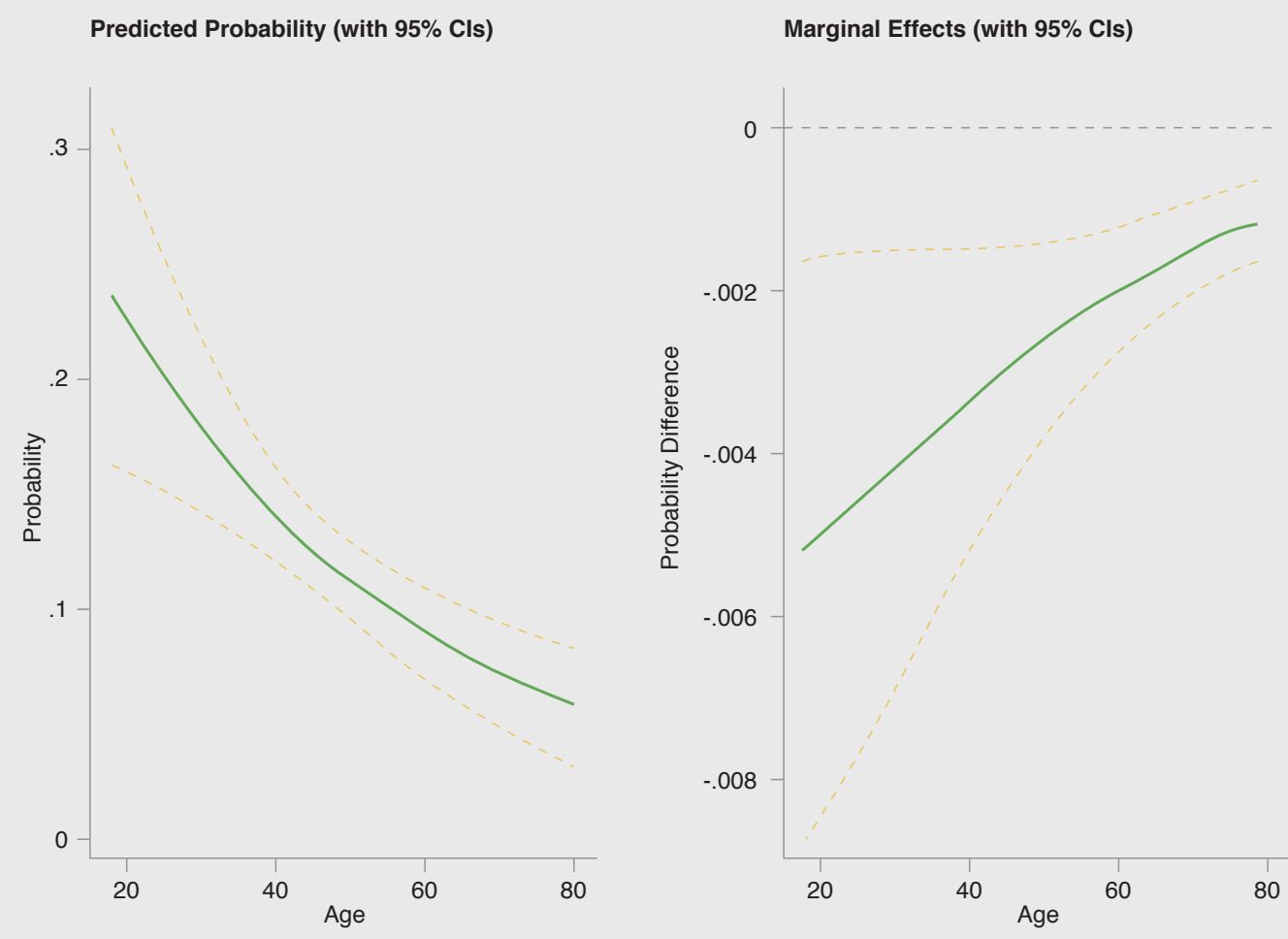

Source: KAPSARC.

Figure A6. Interaction effect of age and postgrad dummy (Model 2).

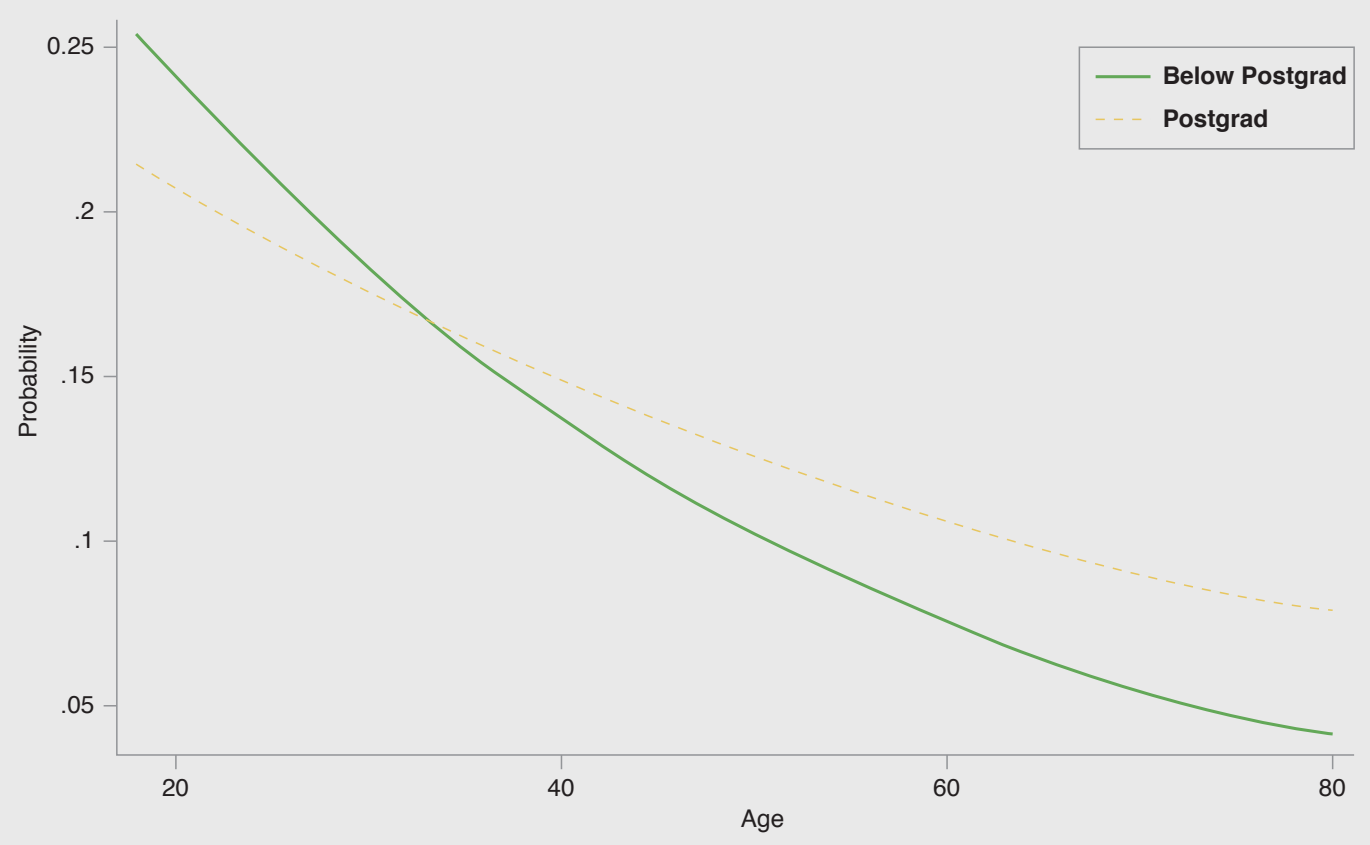

Source: KAPSARC. 
Figure A7. Interaction effect of age and male dummy (Model 2).

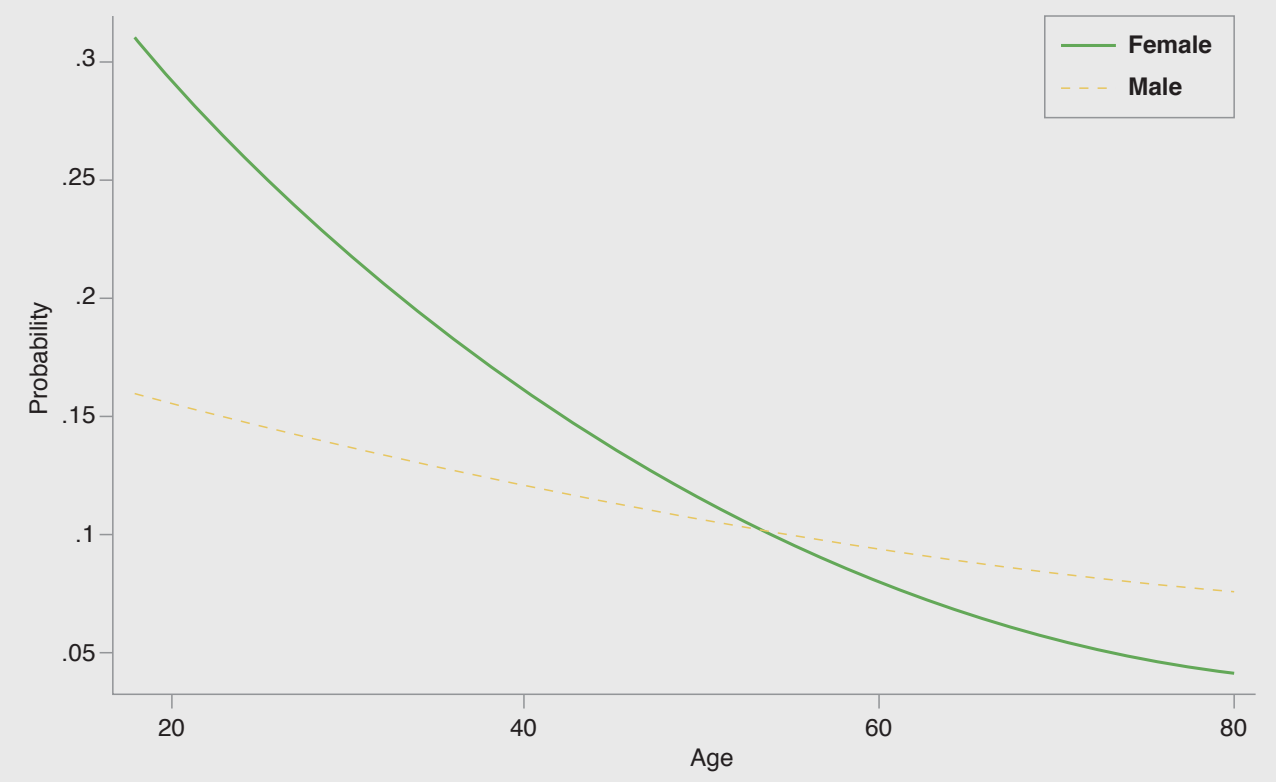

Source: KAPSARC.

Figure A8. Predicted probability and the marginal effect of total vehicle ownership (Model 2).

Predicted Probability (with 95\% Cls)

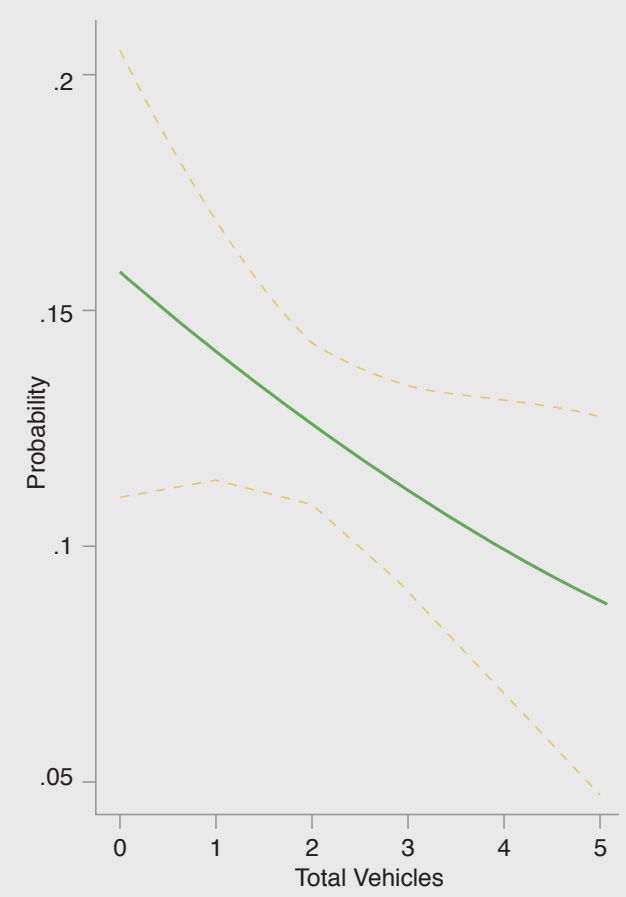

Marginal Effects (with 95\% Cls)



Source: KAPSARC. 
Figure A9. Predicted probability and the marginal effect of age (Model 3).


Source: KAPSARC.

Figure A10. Interaction effect of "age" and "metropolitan resident" dummy (Model 3).

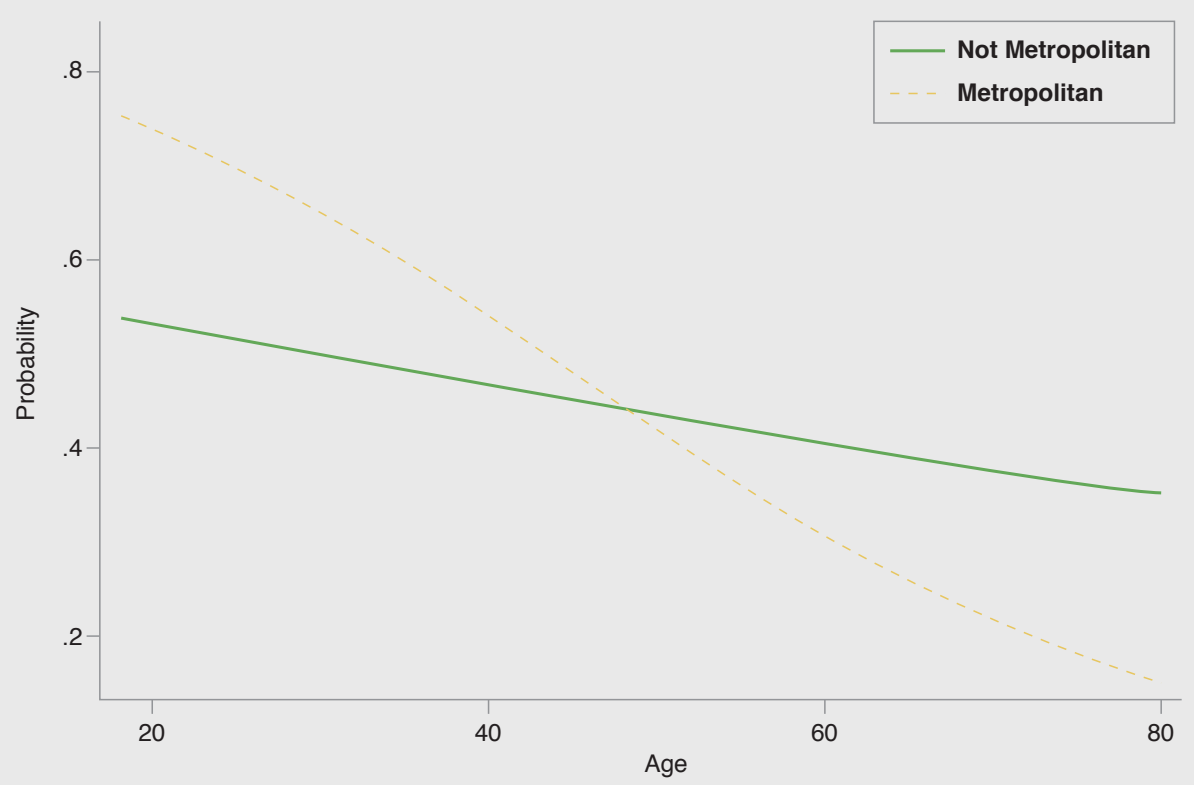

Source: KAPSARC. 
Figure A11. Interaction effect of age and postgrad dummy (Model 3).

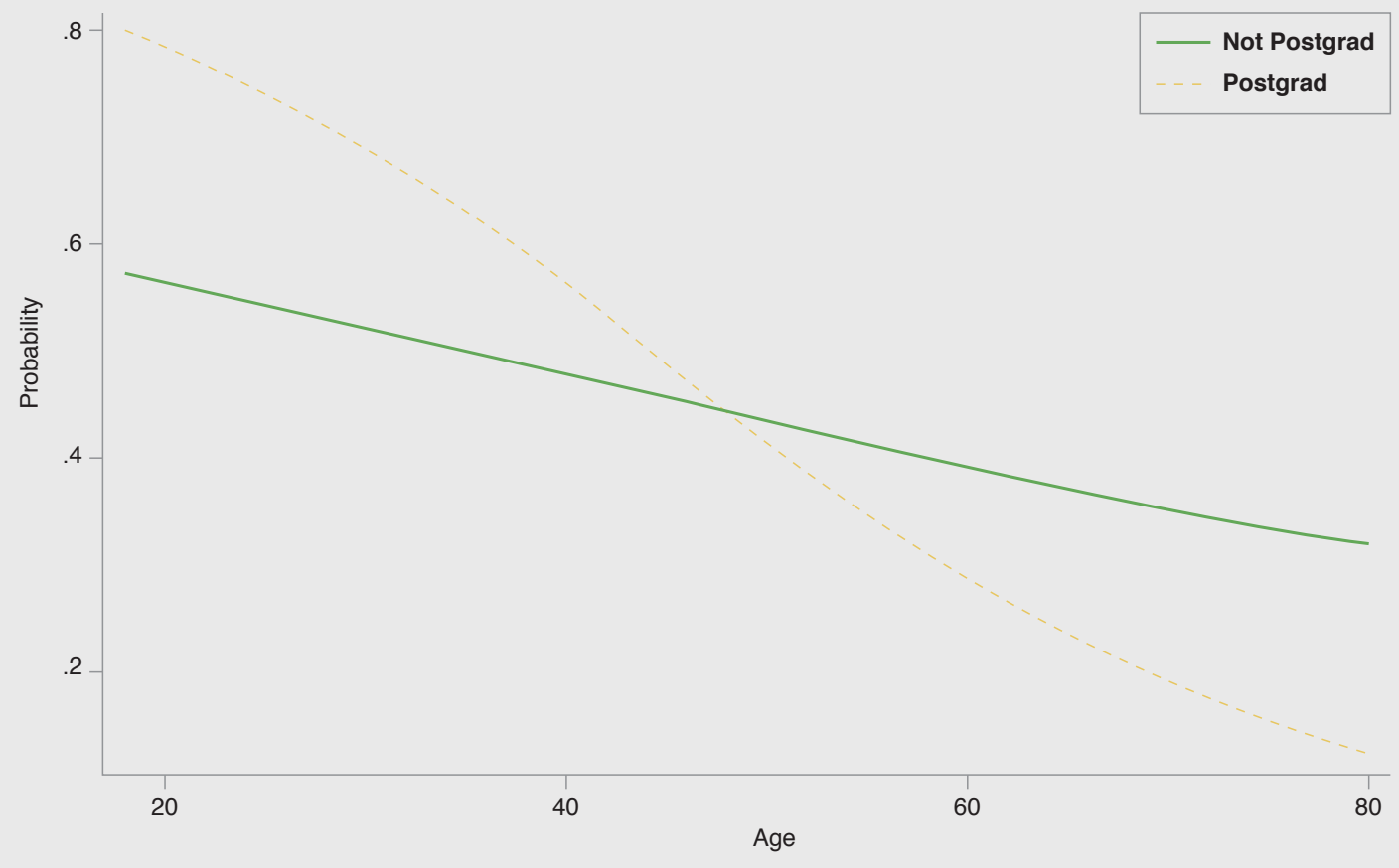

Source: KAPSARC.

Figure A12. Interaction effect of age and single dummy (Model 3).

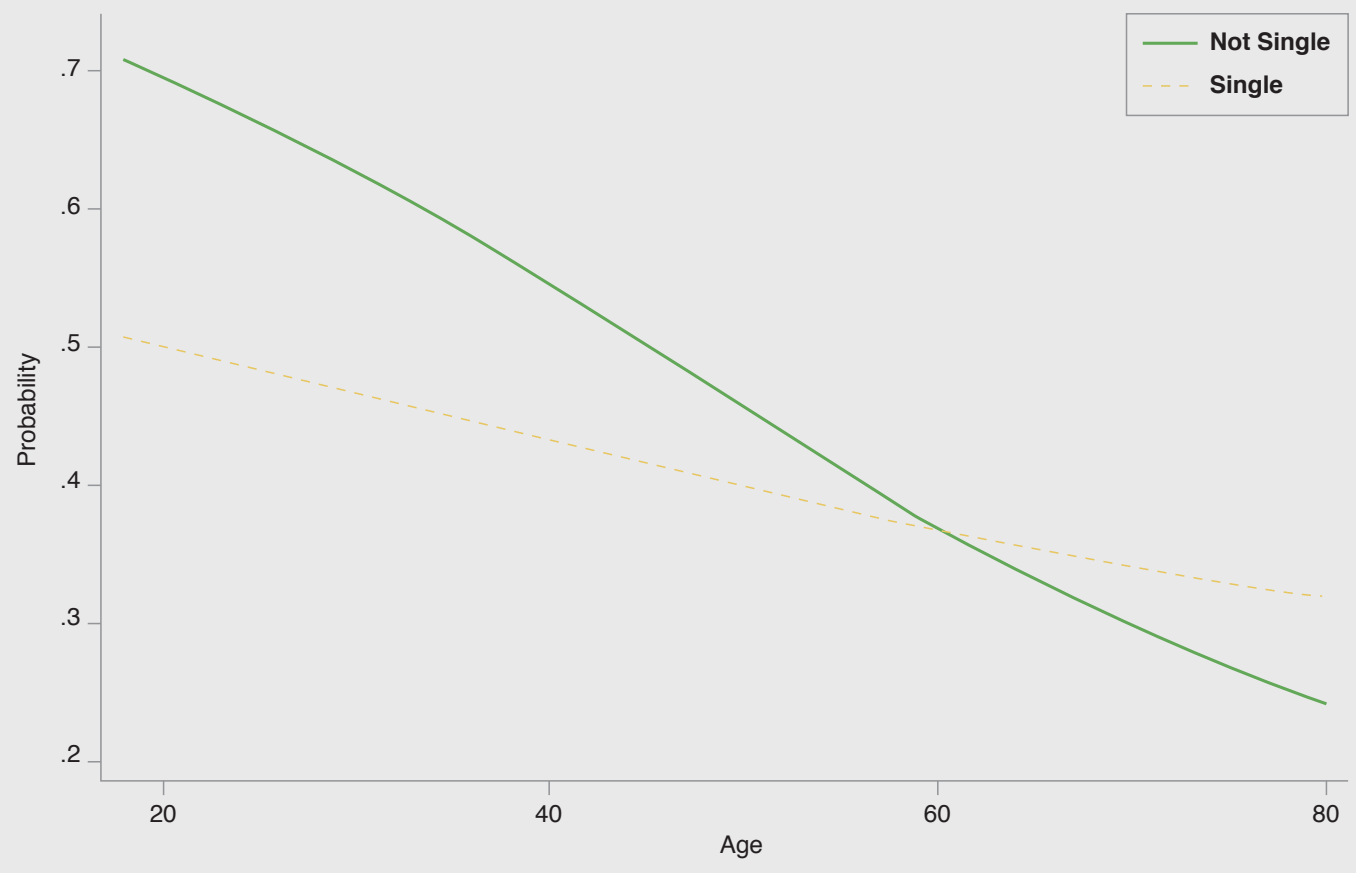

Source: KAPSARC. 
Figure A13. Predicted probability and the marginal effect of total vehicle ownership (Model 3).


Source: KAPSARC.

Figure A14. Predicted probability and the marginal effect of age (Model 4).
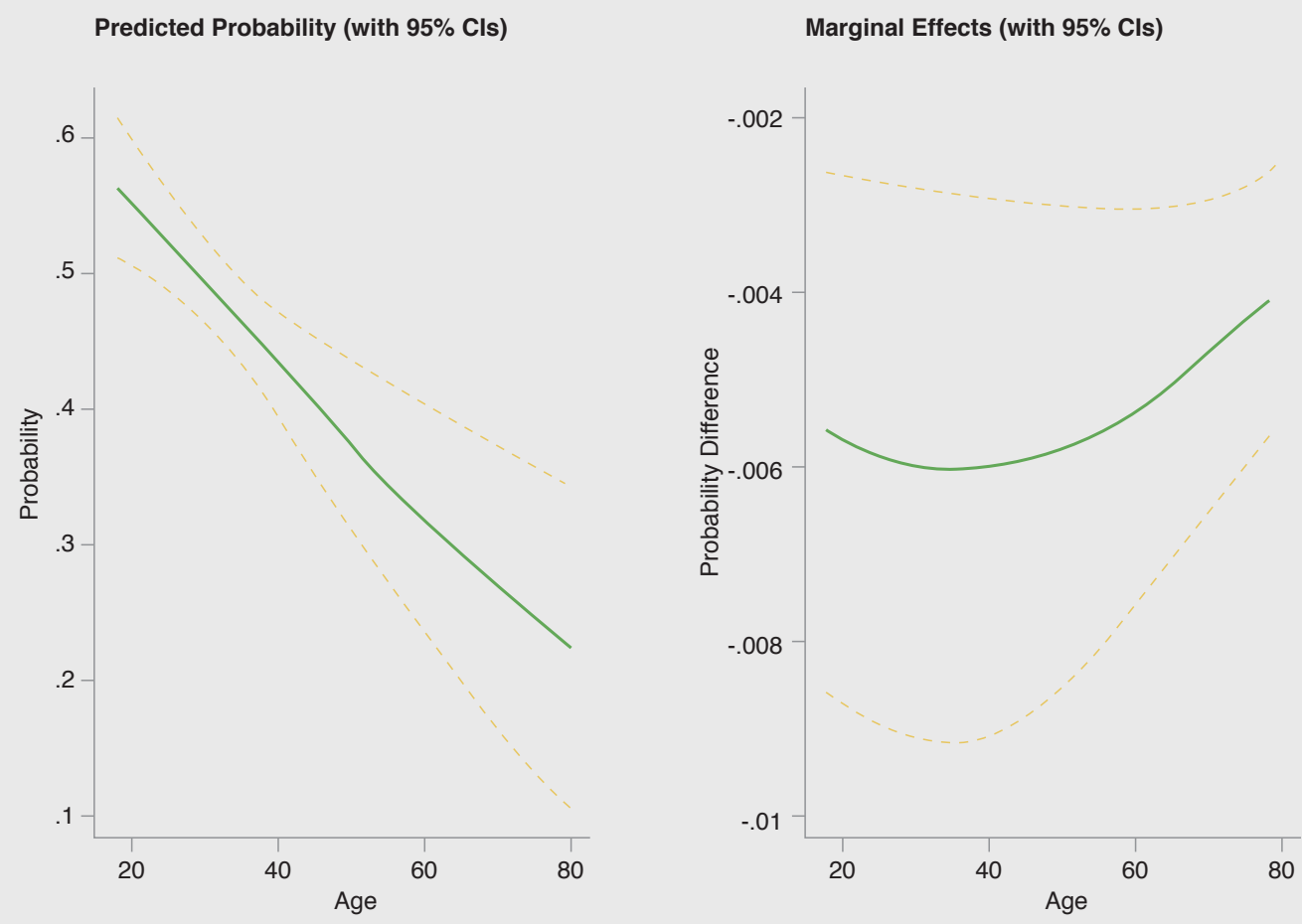

Source: KAPSARC. 
Figure A15. Interaction effect of age and postgrad dummy (Model 4).

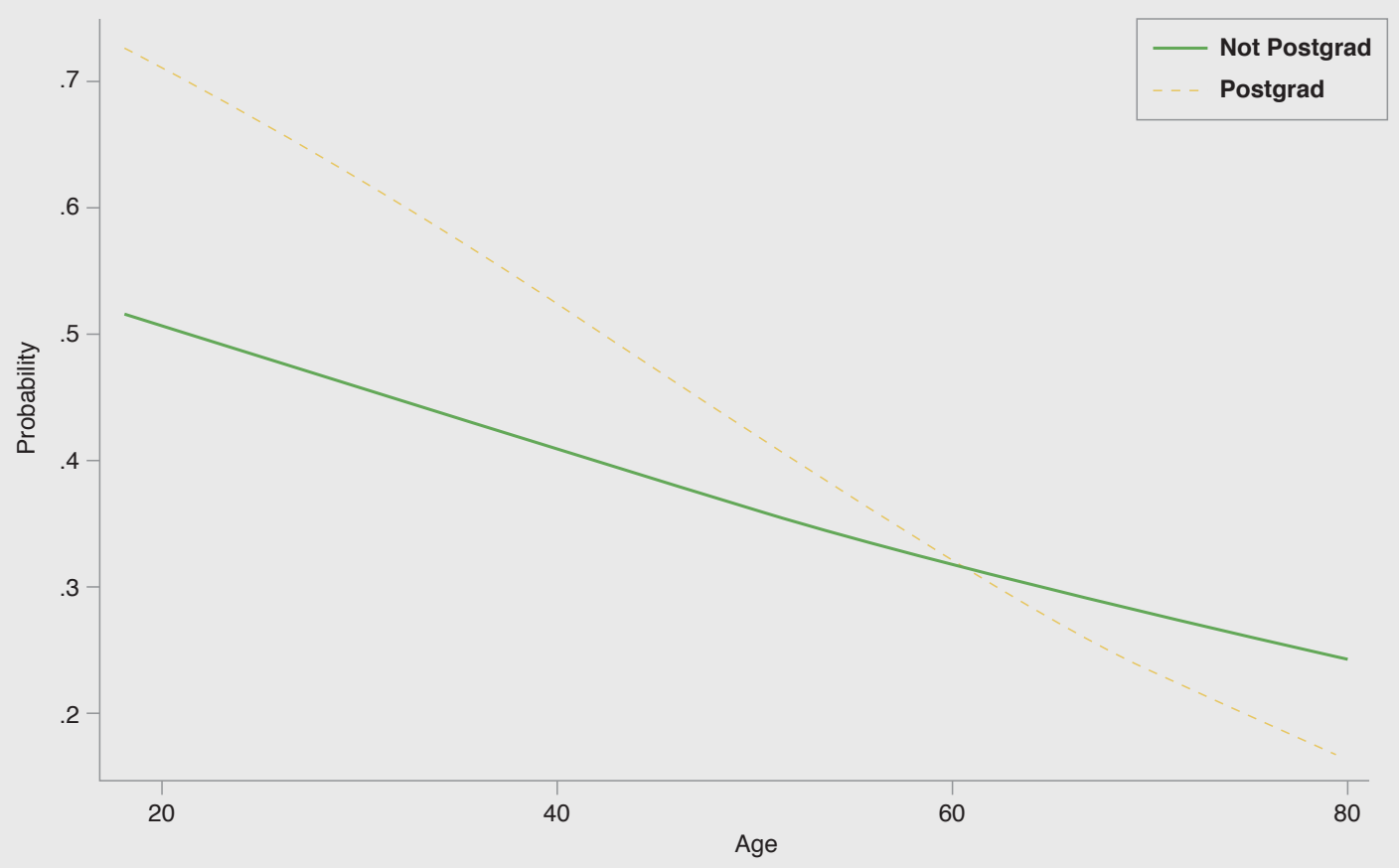

Source: KAPSARC.

Figure A16. Interaction effect of age and single dummy (Model 4).



Source: KAPSARC. 
Figure A17. Predicted probability and the marginal effect of total vehicle ownership (Model 3).
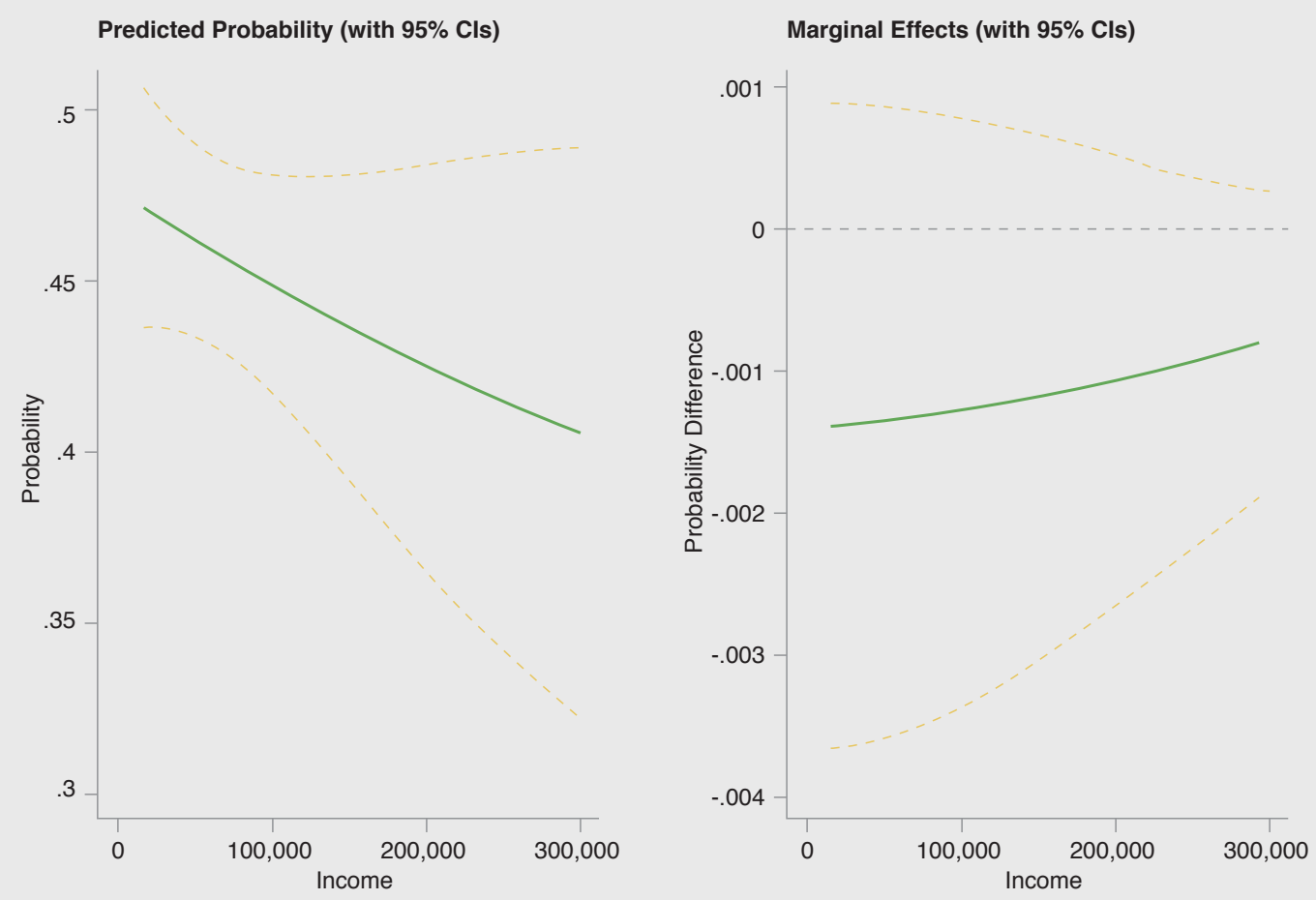

Source: KAPSARC.

Figure A18. Predicted probability and the marginal effect of age (Model 4).

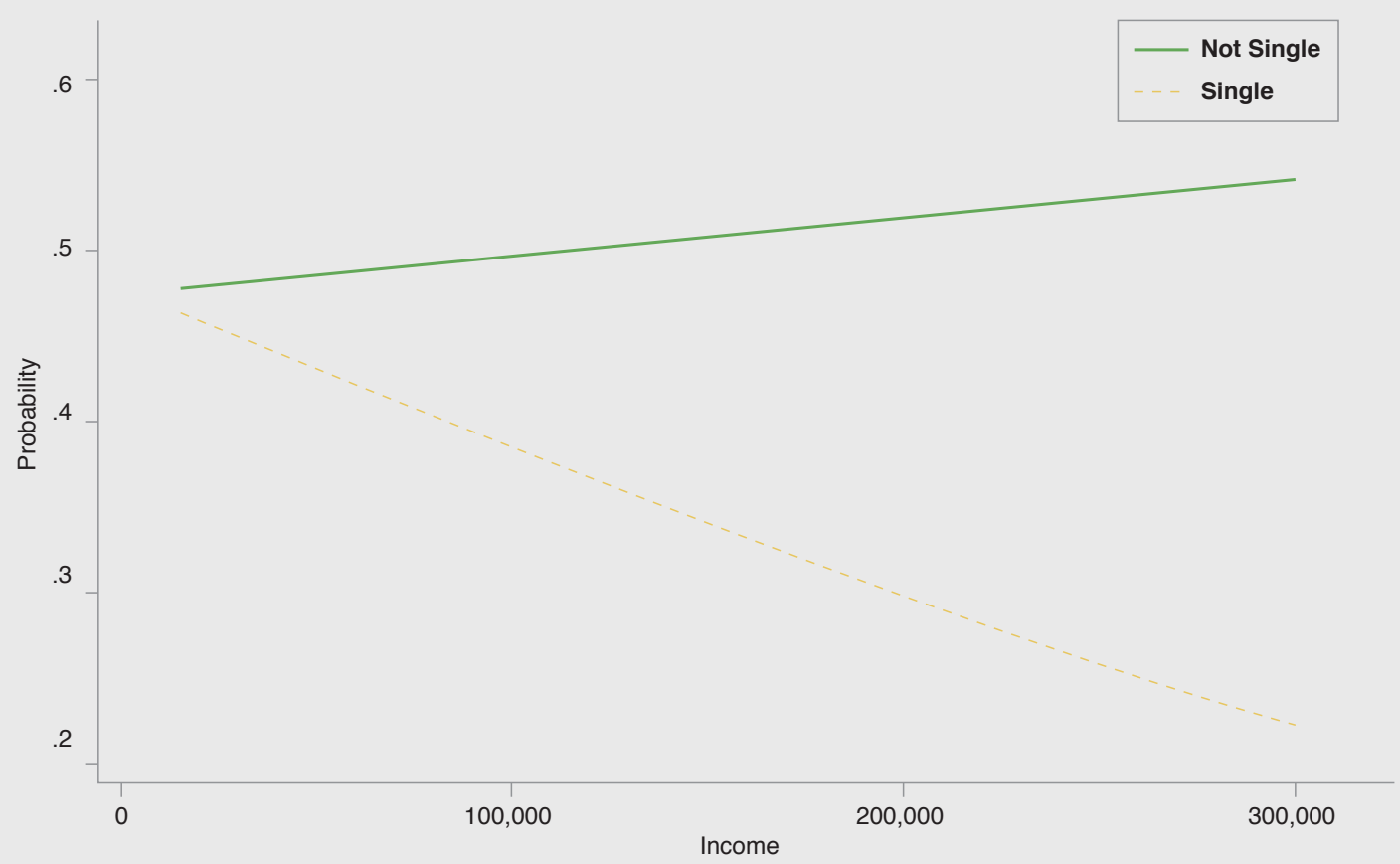

Source: KAPSARC. 


\section{About the Authors}

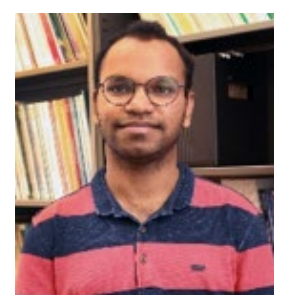

\section{Prateek Bansal}

Prateek Bansal is a postdoctoral research fellow at Imperial College London, working primarily on Bayesian Machine Learning methods and causal inference models with applications in transport systems. He holds a Ph.D. from Cornell University, an M.Sc. degree from The University of Texas at Austin, and a B.Tech. from the Indian Institute of Technology (IIT) Delhi.

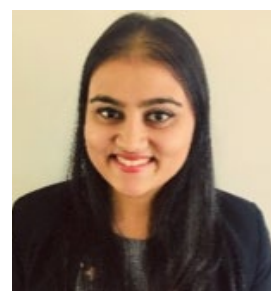

\section{Akanksha Sinha}

Akanksha Sinha is a transportation engineering assistant at DKS Associates where she is working on a variety of transportation projects. She holds an M.Sc. from Cornell University and Colorado State University and a B.Arch from Pune University.

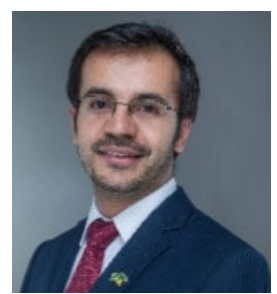

\section{Rubal Dua}

Rubal is a research fellow at KAPSARC working on vehicle regulatory policy and shared mobility research from the consumer perspective. He holds a Ph.D. from KAUST, Saudi Arabia, an M.Sc. from the University of Pennsylvania, and a B.Tech. from the Indian Institute of Technology, Roorkee.

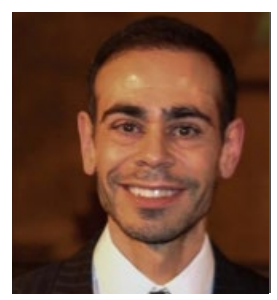

\section{Ricardo Daziano}

Ricardo is an associate professor at the School of Civil and Environmental Engineering and Systems Engineering at Cornell University. His research goal is to better understand the interplay of consumer behavior with engineering, investment, and policy choices for energy-efficient technologies. He holds a Ph.D. in Economics from Laval University, Canada.

\section{About the Project}

The future of light-duty vehicle demand project aims to explore the impact of policy, technology advancements and consumer attitudes on personal mobility choices and energy demand. It focuses on the impact of the rise of mobility-on-demand services on key aspects of travel behavior. The research combines psychographic and demographic data with mobility data to understand the motivations of mobility-on-demand drivers and users and how this will shape the future of energy in both developed and developing economies. 
INAPSARC

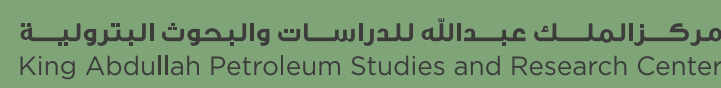

www.kapsarc.org 